NBER WORKING PAPER SERTES

BROTHERS AND SISTERS IN THE

FAMILY AND THE LABOR MARKET

John Bound

Zvi Griliches

Bronwyn H. Hall

Working Paper No. 1476

NATIONAT BUREAU OF ECONOMIC RESEARCH

1050 Massachusetts Avenue

Cambridge, MA 02138

October 1984

The research reported here is part of the NBER's research program in Labor Studies. Any opinions expressed are those of the authors and not those of the National Bureau of Economic Research. 
NBER Working Paper \#1476

october 1984

Brothers and Sisters in the

Family and the Labor Market

ABS TRACT

This paper investigates the relationship between earnings, schooling, and ability for young men and women who entered the labor force during the late $60 \mathrm{~s}$ and 70s. The emphasis is on controlling for both observed and unobserved family characteristics, extending a framework developed earlier by Chamberlain and Griliches (1975) to the analysis of mixed-sex pairs of siblings. Using the Nationa 1 Longitudinal surveys of Young Men and Young Women, which drew much of the sample from the same households, we were able to construct a sample containing roughly 1500 sibling pairs. For several reasons, particularly the need to have data on two siblings from the same family, only one third of these pairs had complete data; this fact led us to develop new methods of estimating factor mode1s, which combines the data for several "unbalanced" covariance matrices. We use the data on different kinds of sibling pairs (male-male, female-female, and male-female) together with these new methods to investigate the question of whether family background, ability, or "IQ" are the same thing for males and females, in the sense that they lead to similar consequences for success in schooling and in the market place. With a simple two factor model to explain wages, schooling and IQ scores, we are able to test whether these factors are the same across siblings of different sexes and whether the loadings on the two factors are similax. The conclusion is that the unobservable factors appear to be the same and play the same role in explaining the IQ and schooling of these siblings, while there remains evidence of differences once they enter the 1 abor market.

John Bound

National Bureau of

Economic Research

1050 Massachusetts Avenue

Cambridge, MA 02138
Zvi Griliches

National Bureau of

Economic Research

1050 Massachusetts Avenue Cambridge, MA 02138

Bronwyn H. Hall

National Bureau of

Economic Research

204 Junipero Serra Boulevard

Palo Alto, CA. 94305 


\title{
Brothers and Sisters in the Family and Labor Market ${ }^{1}$
}

\author{
John Bound, Zvi Griliches, and Bronwyn H. Ha11
}

\section{Introduction}

Most of the earlier work on earnings functions and returns to schooling estimation has been done with male data. Much of the more recent work on the analysis of male-female wage differentials has focused on labor-force participation questions and the correct measurement of work experience and has bypassed the family background-ability-schooling debate which had been conducted largely on the basis of data on males. Thereare a number of stylized facts and conclusions which have emerged from these literatures: In the schoolingability-family background area the conclusion seemed to be that, at least as far as measured IQ and measured family background variables were concerned, their absence did not bias greatly the estimated schooling coefficients in male earnings functions (see Griliches, 1977, and Hauser and Daymont, 1977). The same conclusion also could be reached as far as unmeasured family background is concerned, but here the results were much more sensitive to potential errors in the data which are magnified when within siblings contrasts are used for estimation (see Behrman, et a 1. 1980; Griliches, 1979). As far as male-female comparsons were concerned, the estimated schooling coefficients in wage equations appeared to be somewhat higher for females than for males while the estimated age coefficients were lower for women than for men. These differences were greatly reduced but not entirely eliminated when work experience was 
allowed for. More attention to the quality of the work experience and expectations about labor force attachment reduced the estimated average malefemale differentials somewhat further, without eliminating most of the original differential (see Becker, 1983: Mincer and Polachek, 1974: Sandell and Sehapiro. 1976: and Shackett, 1981). To the extent that the question of "ability bias" was investigated using female data, the conclusions did not differ greatly from those reached using male data.

These debates neither posed clearly nor resolved the question of whether "family background," "ability," or "rQ" are the same thing for males and females, in the sense that they lead to similar consequences for success in schooling and in the market place. Some of the observed differences in market outcomes could arise from a different distribution of abilities across the sexes, different rewards in the labor market to these abilities, and different investment responses by family and individuals.

It is not clear whether such questions can be pursued successfully with the available data. Ideally we would like to have more detail (a sexies of different test scores) and a longer horizon (1ife cycle data) than is wally available in the standard economic surveys. Nevertheless, we would like to open up this question and explore which aspects of it might be answerable with currently available data. We were motivated to pursue this topic by the apparent puzzle thrown up, in passing, in Joyce Shackett's thesis (Harvard, 1981). She found that holding schooling and measured ro constant. there is sti11 an unaccounted for correlation in wages between brothers and between sisters, indicating the presence of an unmeasured family related component of "ability" or marketable human capital. But when she examined brother-sister pairs in a similar fashion, their wage residuals were essentially uncorrelated, suggesting the possibility that "abilities" are either distributed differentially among males and females or priced differently in the market. 
To check such conjectures and to interpret them in a broader context, we have updated Shackett's data and extended the framework developed earlier by Chamber 1 a in and Griliches (1975 and 1977) to the analysis of mixed-sex pairs. Our analysis is based on the NLS Young Men and Young Women tapes which contain information on roughly 1500 sibling pairs (male, female, and mixed) over the 1966-1980 period, including IQ test scores for about two thirds of the individuals. Unfortunate1y, the data are rarely complete for both members of a sibling pair. Only about one third of the pairs (about 150 to 200 pairs each) have complete data on all the variables of interest. This has led us to adopt and develop new methods of estimating such mode1s, combining data from several "unbalanced" moment matrices, i.e., matrices with rows and colums missing (corresponding to the variables for which data are missing in the particular observationa 1 subset).

We cannot really test directly the hypothesis that "abilities" are distributed differently across males and females or that they are priced differently, whont having information on a number of different test scores for both men and women. What we can do is, first, to check whether the observed empixical fact persists in a more complete unobserved factors mode1 which a 11 ows both IQ and schooling to be measured with error, second, to investigate whether this cross-sex difference appears only in wages or can be traced back to the earlier IQ-schooling relationship; and finally, we can ask whether the data imply the presence of more than one ability factor in the sense that the male and female versions of the ability factor are not perfectly correlated.

The basic approach of this paper is to specify a relatively simple mode 1 with two common factors for the observed data (test scores, schooling, and two wages: early and late), one factor reflecting unobserved "ability" and the other measuring common endowments across siblings which are orthogonal to ability, 
e.g. wealth. This model is estimated on data for brother-brotber. sistersister, and brothex-sister pais, allowing both the factor loadings and the factors themselves to differ across the sexes. Using this framework, it is possible to test whethew the factor structure is alike for males and females, in the sense that the estimated factor loadings are similat for the two sexes, and whether the male and female factors are the same, that ss, bave a correlation of unity.

In implementing oux model we have chosen to sweep ont all of the other exogenous variables contained in these equations, both to simplify the computations and because our samples of men and women have not been drawn in a completely identical fashion; for example, the survey of men begins in 1966 and that for women in 1968. Accordingly we have removed age, xace, region, city residence and the constant freely from all of the dependent variables and separately for males and females. Thus, the main male-female difference in the level of wages is already taken out in the first pass at the data and is not explained by the model. The focus of this paper is on the differences in the stracture and influence of the unmeasured family components actoss the two sexes.

The plan of the paper is as follows: First, we outline briefly a simple model of $1 Q$, schooling, and wages in the context of sibling ata and explain what we are after. Second, describe our data and outline the specific estimation problems caused by the relatively high frequency of missing data for one or both of the siblings. Thicd, we present the results of estimating the complete model and thendiscuss the results of testing the equality of the factor structure across siblings. Finally, we venture some conclusions relating to the more general topic of male-female differences in earnings. 


\section{The Mode1}

Consider the standard earnings equation

1)

$$
L W=a+\beta S+\gamma I+\delta X+\mathfrak{n}
$$

where LW is the logarithm of wage rates or earnings per some time unit, $S$ is the level of schooling, $I$ is a score on an "intelligence" test, $X$ represents a set of other variables which we shall not consider explicitly here, snch as age, race, and region; $\alpha, \beta, \gamma$, and $\delta$ is a set of parameters to be estimated, and a represents a 11 other unmeasured determinants of wages, including unmeasured but relatively permanent differences in human capital levels across individuals and transitory fluctuations and measurement exrors in wages and other variables. The usual discussion in this area (e.g., Griliches, 1977) proceeds to focus on the estimation of $\beta$, the "rate of return to schooling," in the presence of a number of potentially complicating circumstances: the lack of a good "ability" varlable and/or the use of a particulax errorprone test score as a proxy for it, and the possibility both of exrors of measurement in achieved schooling levels and of endogeneity, in the sense that schooling may be chosen in anticipation, and with the knowledge, of some of the components of a (which is unobservable to the analyst). As stated, $\beta$ is unidentified in this model in the absence of addional instrumenta 1 variables such as measured backgrond variables which would affect $S$ and $I$ without themselves entering the LW equation directly. In this context, sibling data are interesting because they provide another way of ldentifying $\beta$ by using the sibling values of $S$ and $I$ as instruments. Eaxller work of this type focused primarily on 
male siblings (see Griliches, 1979, for a review) and this is one of

the first papers to look also at sister and brother-sister pairs (see a 1 so Scarr and MacAvay, 1982).

In work that focuses on male-female wage differentials, the question is often whether the estimated differences in $\alpha$ and $\beta$ can be explained by incorrect measurement of the components of $X$ (such as different meanings of work experience for the two sexes) or by Pollachek, to identify and sibling data cannot be used are, they and interpret what these unobservable components "real1y" extent, sex specific. Consider the following simplified factor model for $I Q$, schooling, and wage:

(2) $I=$

$$
\gamma_{1} \mathrm{~A} \quad+\mathrm{u}_{1}
$$$$
s=\quad \gamma_{2} A+\eta W+u_{2}
$$

$$
L W=\beta S+\gamma_{3} A \quad+u_{3}=\left(\beta \gamma_{2}+\gamma_{3}\right) A+\beta \eta W+\beta u_{2}+u_{3}
$$

where the story differs from the earlier one [eq. 1] in having "sweptout" in an unconstrained fashion the other $X$ variables to simplify both exposition and computation. The model contains an unobservable ability factor A, for which I (an IQ-type score) is an error prone proxy. "Ability" affects achieved schooling levels and may also enter the wage equations direct1y, above and beyond its indirect effect via schooling. In addition there is a "wealth" factor W, which affects only schooling 
directly. The following notational definitions and no-correlation assumptions are made:

$$
\begin{aligned}
& \mathrm{EA}^{2}=\mathrm{a}^{2} \quad \mathrm{EW}^{2}=w^{2} \quad \mathrm{Eu}_{\mathrm{j}}{ }^{2}=\sigma_{\mathrm{j}}{ }^{2} \\
& \mathrm{EAW}=\mathrm{EAu_{j }}=\mathrm{EWu}_{\mathbf{j}}=\mathbf{0} \\
& E \mathfrak{u}_{1} \mathfrak{u}_{j}=0 \quad \text { for } j \neq 1 \\
& \mathrm{Eu}_{2} \mathrm{u}_{3}=\sigma_{23}
\end{aligned}
$$

The statements above reflect the following assumptions: The $A$ and W factors are orthogonal, i.e., is the "wealth" component that is above and beyond that part of wealth that is already correlated with the ability factor. (That $A$ and are orthogonal is a convenient normalization. Some such rotational assumption is required for the separate identification of the factor coefficients.) These factors are assumed to be independent of all the equation specific disturbances. The exror in the test score $u_{1}$ is a pure measurement error antransmitted to other equations and uncorrelated with the other disturbances. Because $S$ may be measured with error in (2), or ma be chosen endogenously, $\mathrm{a}_{2}$ is allowed to be freely correlated with ${ }_{3}$. As written, and in the absence of additional instrumental variables or restrictions, this model is heavily underidentified. This can be most easily seen by counting the number of unknown parameters nine, relative to the number of the observed variances and covariances, which is only six.

It is the availability of sibling data which allows us to identify the parameters of such a mode1. Denoting pair members by a and b or m 
and $f$ subscripts, and treating them symmetrically (i.e., we assume that siblings have the same variances and coefficients, at least as long as they are of the same sex), we make the following additional as sumptions :

$$
\begin{aligned}
& \text { (4) } \mathrm{A}=\mathrm{f}+\mathrm{g}, \quad \mathrm{Ef}^{2}=1, \quad \mathrm{Eg}^{2}=\tau, \quad \mathrm{W}_{1}=\mathrm{w}_{2}, \quad \mathrm{w}^{2}=1 \\
& E u_{1 a} u_{1 b}=E u_{2 a} u_{2 b}=E u_{1 a} u_{2 b}=E u_{1 a} a_{3 b}=0 \\
& E u_{2 a} u_{1 b}=E u_{2 a} u_{3 b}=E u_{3 a} u_{2 b}=0 \\
& \mathrm{EWu}_{\mathbf{j k}}=0 \quad \text { for } \mathbf{j}=1, \ldots, 3 \text { and } \mathrm{k}=\mathrm{a}, \mathrm{b} \\
& E u_{3 a} u_{3 b}=\sigma_{a b}^{2}
\end{aligned}
$$

which imply the following: A is a factor with a family variance components structure with $f$ representing the family component and $g$ the individual one. We normalize so that the variance of $f$ is one and the variance of $g$ is $\tau$. W, on the other hand, is a pure family factor with no individual components and is normalized to have a variance of one. A11 of the cross-sibling correlations in $I$ and $S$ are assumed to be captured by the two family components $f$ and $W$, and hence $u_{2}$ is not correlated with the other sibling's $u_{3}$, though it is allowed to be freely correlated with its own. The residuals in the wage equations are allowed, however, a free family structure.

Note that, under the condition that we do not distinguish between siblings, we are adding six covariances but only two parameters and the model is now identified. Figure 1 makes clear where identification comes from. Factor loadings, the schooling coefficient $\beta$ and the cross-sib wage covariance are all identified within the cross-sib 
matrix with the own-sib covatiances then identifying the individual residual variances and covariances. 2 The model is recursive with the cross-sib IQ covariance identifying $\gamma_{1}$, the schooling covariances identifying $\gamma_{2}$ and $\eta$, and then the wage covariances identifying $\gamma_{3}, \beta$ and $\sigma_{3} \mathbf{a b}$

The above is a variant of the standard way of identifying the schooling coefficient in a wage equation, using a proxy for ability and instrumenting both schooling and the proxy with family background variables. An advantage of setting up the model in terms of covariance matrices rather than a standard IV setup is that then it can be easily generalized to allow for another index for the sex of the sibling. We assume that the model specified above applies to each sex separately but that there may be a sex specific component to each factor. This implies that the factors will be less than perfectly corcelated, and introduces two additional parameters, $\rho_{A}$ and $\rho_{W}$ representing the correlation between the male and female version of each factor. We a1so allow for free correlations across the brothers and sisters' wages. The bottom panel of Figure 1 shows the cross-sex cross-sib covariance matrix implied by this model. Note that the factor loadings are also assumed to be different for the two sexes.

To test the hypotheses mentioned in the introduction, we ask, essentia11y, how we 11 a factor structure identified within the brother and sister pairs separately can rationalize the cross-sex cross-sib covariance matrix. With the model as specified, it is not too difficult to fit the same-sex covariance matrices since we are fitting 12 covariances with 11 parameters but the test on the cross-sex matrix is more stringent. We add nine covariances but only three parameters 
$\left(\rho_{A}, \rho_{W}\right.$ and $\left.\sigma_{3 m f}\right)$. The sequence of tests we will use is the following: First, the test of equality across the sexes of the wage covatiances is a test of whether there are still significant differences in the family effect after controling for ability. Second, we test whether ability is priced differently for men and women by testing the equality of the factor loadings. Pinally the test that $\rho_{A}$ and $\rho_{\text {W }}$ are unity is a test that the factors have no sex specific structure.

Before we turn to a moxe detaled description of our data and estimation procedures, several additional points should be mentioned: the ase of age instead of experience in our list of predetermined variables and the interpretative differences this implies, the use of two wage variables. and the notu-use of measured family background variables. Most of the work in this area (e.g... Grillebes 1977 and Mincer 1974) uses accumulated woy experience as a variable in the wage equation and defines the schooling coefficient as estimating the effect of schooling "holding work experience constant." Experience is ustally entered in non-linear fashion and is a function of age, schooling, and other factors which deterine the post-school labor force paticipation and employment experience of an individual. From oux point of wew this interpretation of expexience is endogenous to the achievement mode1. Given the potential nonlinearity of its effect, it would be rather afficult to extend our models to incorporate it explicitry. We can think then of onr model as one in which this variable has been solwed ont, leaving one of its determinants. age, among the predetermined $\mathrm{x}$ yariables. But since the usual schooling coeficient estionates are based on equations of the formbs + d Age - $S$ 6), our results are to be interpteted as estimating (b-d)s + AAGE. Thus, to compare onx estimated schooling coefficients $\beta$ to earlier 
estimates in the literature requires the addition of the estimated age coefficient to them.

This paper differs from our earlier efforts (ChamberlainGriliches, 1975 and 1977) by including two wage variables in the model, early and 1ate. We do not focus, however, on the wage or earnings growth profiles explicit1y (on that, see Chamberlain, 1978, for examp 1e). Moreover, since we do not include work experience in the wage equations directly, we do not constrain either the schooling coefficients or the ability coefficients to be the same in the two wage equations. Implicit1y, this allows for an age-schooling interaction in the wage equation, which we could not allow for explicitly.

It a 1 so differs from some of the other papers in this area by not including measured family variables such as father's occupation and mother's education in the equations to be estimated. Using sibling data they are subsumed instead in the unobservable fanily factors $f$ and W. One might be tempted to use them also in a more elaborate MIMIC type mode1, but the mode1 to be used by us is already straining our computational resources and the ability of the data to discrimirate between its various sightly different versions. 


\section{Data and Variables}

Our data come from the National Longitudinal Survey of Young Men (19661980) and Young Women (1968-1980). (See Centex for Human Resource Research. 1979. for a detaled description.) These surveys started with about 5000 respondents each, and re down to about 4000 interviewees each by the end of the last decade (the attrition is for such reasons as death, inability to locate. and refusal to answer). When these surveys were originally designed (including the Older Men and Mature Women panels), they were chosen in a stratified randow cashion from a larger anderlying household sampling frame. rats has led to the presence of a number of same household members within and across different panels. In particular, it is possible to identify approximately 703 households with at least two brothers, 668 households with at Least two sisters, and 1075 with at least one brother-sister pair. The cohoxts covered were oxigina 114 to 24 gears $01 d$ in 1966 for males, and 14 to 24 years old in 1968 for females. The latest surveys available to us at the time this analysis was initiated followed them through 1980 with the age of respondents xarging from 28 through 38 for males and from 26 through 36 for females.

We have tried to use the data for all the individuals who finished schooling before ot during the survey periods and for whom we could construct the requalite data. We use data from three points in these surveys: (1) first Hintervidy data (1966 for men, 1968 for women) for age, race, and rQ test scoxes collected from the respondents high schools ${ }^{3}$ (missing for about one-third of the sample). (2) Schooling level achieved at completion of school (in years) and wage received on an "evaly job" (after leaving school, not before age 18 and axowal 22 if data are avalable, later it the school leaving age was higher) and other associated vaciables at that juncture (age, region, city size, and 
marital status). And (3) a "later" wage (around age 28, but at least three years later thon the early wage) with the same set of associated variables as of that date. The rules we followed in selecting our abservations and constructing our variables are described in greater detail in Appendix $B$.

Table 1 shows the sample sizes which resulted when we made various cuts on good data and gives some idea of the relatively small fraction of our observations which contains data on siblings. Among the original 10,000 or so respondents, it was possible to identify about 1600 pairs or ronghly $3000+$ individuals who had a sibling in one of these surveys. By the time we ask that both siblings should have completed school, had observations on both an early and later wage and data on IQ scores, we are down to less than one third of the original number: about 520 pairs or 1040 individuals (see the first 1 ine of the bottom panel of Table 1). The major attrition occurs due to missing IQ scores and issing late wage (due to attrition from the sample, late school leaving, or non labor force participation). Overall attrition is slightly higher for males than females.

From the point of view of our mode1, we are missing ata for two quite different reasons: first, because of the usual problems with sample attrition and nonresponse, many observations have missing values for one or more variables. Second, each male or female in the sample may or may not have both a brother and a sister frov which we can obtain a full set of covariances. It turns out that both these problems can be solved in the same way, enabling us to use the maximal amount of the available data, rather than restricting the estimation to the subsample which is complete. We describe the methodology for obtaining such estimates in the next section of the paper, and focus here on more general data selection problems and sample description.

Table 1 shows that we are relatively short on complete data and on data for 
same-sexed pairs. Our data selection strategy was designed around this. First, for families with only one or two individuals in the original sample (most of our data) the assignment to a particular matrix was unambiguous. For families with three or more siblings, however, we we forced to make selections to avoid using individuals more than once. We ordered sibs by data availability and then assigned all the conplete data pairs we could to the brother-brother and sistersister complete data pairs. The remainder of the complete data pairs were assigned to the cross-sex matrix. All the remaining siblings were either assigned to a pair with some data missing, or if no data remained on their sibling, they were placed with the residuals and treated as individuals. The consequence of this procedure was to leave us with a nearly balanced design in terms of the number of brother, sister, and brother-sister pairs in the data. Families are sometimes represented more than once, but for the vast majority this means that a non-matched individual rarely has sibs in the sib-pair matrices. 4

This process yie1ded 24 different moment matrices with the observations and data patterns given in the bottom panel of Table 1. Each person from the original sample who has a good observation on completed schooling has been placed in one of these matrices. In section 4 we describe how we combined the information in these different matrices when estimating the rodel.

Table 2 gives the means of the variables in our data. There are no sutprises in the male-female differences: the average male wage is higher, and seems to grow somewhat faster (with a caveat due to the changing sample) and the male varianoes are higher for our key endogenons variables. Pecause the original surveys oversampled blacks, our samples have a significantly larger non-white proportion (.29) and more respondents in the South (.36) than is true of the general U.S. population. Given that non-whites tend to have laxger families, this is cyen mote so for our sibling data. Fxcept for including race and region 
as conditioning variables we have made no furtber adjustments for this discrepancy from national representativenes.

The table also shows that the average age of our respondents is 23 at the early wage date and 27 at the later one. This is stil quite early in their labor force careers and just before or approaching Mincer s (1974) "overtaking" point. Thus, our results have to be interpreted remembering the relative youth of these respondents.

In the next section, we describe the method of estimation which we used; it essential1y involves fitting our model to several matrices of variances and covariances of the data simultaneously. Because of this, erch additional variable we include tends to be rather expensive in terms of computational costs. This has led as to preprocess the variables of interest by regressing each of them on a set of exogenous variables and asing the residuals from these regressions to form the covariance matrices from which we estimate the parameters of interest. From MaCurdy (1981) we know that the estimates of the parameters of the covariance matrix (including the structural coefficient $\beta$ ) which are obtained conditional on these regression estimates are consistent and asymptotica11y normal1y distributed with a covariance matrix which does not depend on the fact that we preprocessed the variables in this way. We give the details of these first stage regressions in Appendix B; briefly, the variables we removed were the appropriately dated race, age, and region of residence variables (at the initial survey date for schooling and IQ, at the date of the observation for the wages) and dummes corresponding to the data sample (that is, the covariance matrix) into which an observation falls. These dummies adjust for missing data which may be random 1 y missing conditiona on the unobservables but stil1 not randomiy missing unconditionally. 5 


\section{Econometric Methodology}

The model we are estimating can be thought of as consisting of eight equations (four "dependent" variables - I, S, LW1 and LW2, for each of the two siblings). A version of this mode1 with only one wage variable is depicted in Figure 1. If one assumes that conditional on the exogenous $X$ 's (which have been swept out freely by the preprocessing) the observed variables are distributed according to multivariate normal distribution, then the observed moment matrix is a sufficient statistic. Figure 1 gives the expected values for the components of this matrix conditional on the correctness of our assumed model.

Many econometric models can be written in the form $\Omega(\theta)$, where $\Omega(\theta)$ is the true population covariance matrix associated with the assumed multivariate normal distribution, and $\theta$ is a vector of parameters of interest. Denote the observed covariance matrix by $S$. Then maximizing the likelihood function of the data with respect to the model parameters comes down to maximizing

$$
\ln L(\Omega \mid S, \theta)=k-(n / 2)\left[\ln |\Omega(\theta)|+\operatorname{tr} \Omega(\theta)^{-1} S\right]
$$

with respect to $\theta$. If $\theta$ is exactly identified, the estimates are unique and can be solved directly from the definition of $\mathbb{Q}$ and the assumption that $S$ is a consistent estimator of it. If $\Omega(\theta)$ is overidentified, then the maximu likelihood procedure "fits" the mode $1 \Omega(\theta)$ to the data $S$ so as to maximize the likelihood. This can be done either using the LISREL program (Jorestog and Sorbom 1981) or the MOMENTS program (B. H. Ha11 1979). If the observed variables are multivariate normal this estimator is the full information maximati likelihood estimator for this model. Even if the data are not multivariate normal but follow some other distribution satisfying mild regularity conditions 6 
with $E(S \mid \theta)=\Omega(\theta)$, this is a pseudo- or quasi-maximum likelihood estimator yielding a consistent estimator of $\theta$. In this case, however, the asymptotic variance of the estimator is somewhat more complicated to compute and the standard programs do not produce the correct answer. A later version of this paper will contain estimates of the standard errors which are robust to nonnormality of the data.

This is fine for a random sample from the underlying population with all the variables present. But what is to be done if for one-third of the sample one is missing measurements on one of the variables (say $I$ ) or with observations which have no sibling data at a11? In such situations one can think of the observed matrix $S$ for one or more of the relevant sub-samples as missing one (or more) rows and columns.

There is no conceptual difficulty in generalizing the sample matrix approach to a multiple sample situation where the resulting $\Omega_{j}\left(\theta_{j}\right)$ may depend on somewhat different parameters. As long as the different matrices can be taked as arising independently, the ir respective contributions to the likelihood function can be added $u p$, and as long as the $\theta_{j}$ 's have parameters in common, there is a return from estimating them jointly. This can be done either utilizing the multiple samples feature of LISRELV (see Allison, 1981), or by extending the MOMENTS program (Ha11, 1979) to the connected-multiple matrices case. The estimation procedure combines these different matrices and their associated pieces of the likelihood function, and then iterates across them until a maximum is found. A more detailed description of the mechanics of this approach is given in Appendix C.

The main assumption required for the consistency of this approach in the context of missing data is our ability to treat the various sub-samples as independent pieces of the likelihood function. That is, we have to assume no 
significant sample selection or self-selection problem, treating our data as if the missing pieces are missing at random. This does not mean that the expected value of missing data is the same in all the matrices, only that (in the newer terminology of Rubin 1976 and Little 1982) the data generation process is ignorable in the sense that the desired parameters can be estimated consistently from the complete data subsets and that "missing data" methods use the rest of the available data only to improve the efficiency of such estimates.

To be more precise, the distribution of the missing data must be, conditional on the distribution of the available data, independent of the fact that it is missing. This condition justifies integrating the full likelihood over the distribution of the missing data to get a marginal distribution for the partially observed data. The marginal distribution, sharing parameters of the original, can add information to our estimates even when not all would be identified in the partially observed data alone.

While these conditions are unlikely to hold exactly in practice, we do expect them to bold approxinate1y. The presence or absence of siblings is likely to be random with respect to the parameters of interest to us. Attrition and labor foxee participation (especially for young women) is likely to be nonrandom with respect to the unobserved wage components, but earlier work on sample selectivity bias in both of these areas (Griliches, Hausman, Ha11, 1978; Smith, 1980) has not uncovered a consistent and large biasing effect. While we do know that $I Q$ is not missing randomly in an overall sense, conditionally on our $X^{\prime} s$ and the unobserved factors it too may be issing at random.

We shall proceed assuming that it is indeed legitimate for us to pool these various matrices. It would be possible to investigate the issue further, but we sha.1 not do that here. Under the maintained assumption, our parameter estimates should change little as we include more data. We have estimated the 
mode 1 using various amounts of the incomplete data and have found fe qualitative differences. As an example, results using only the complete dat are reported in an appendix. 


\section{Results}

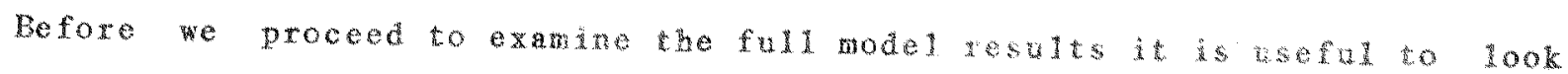

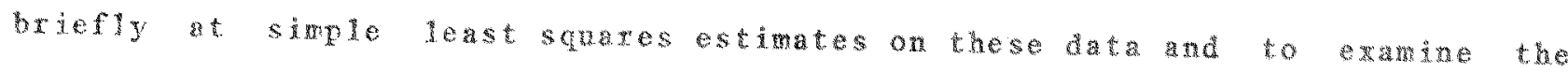

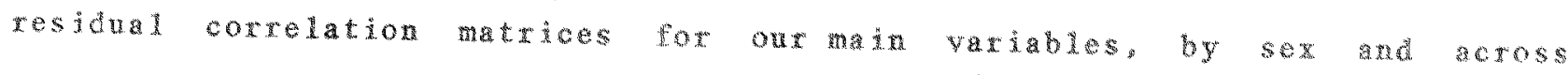

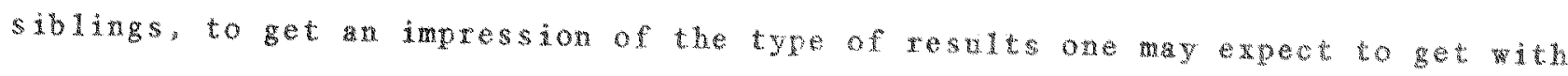

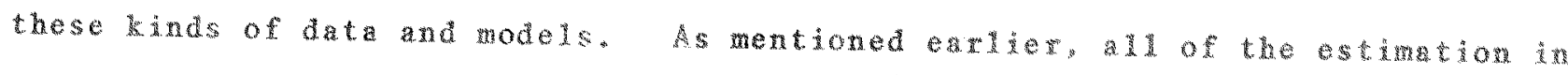

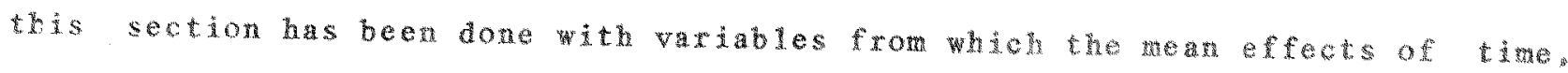

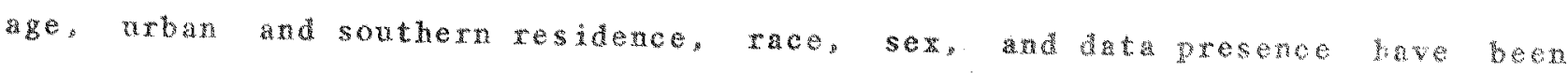
removed using wncoustarined teduced form tegressions.

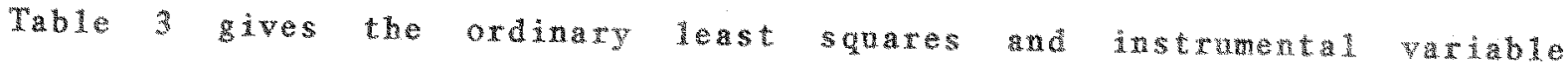
estimates of a standard earuings equation for the brotwes and sustes

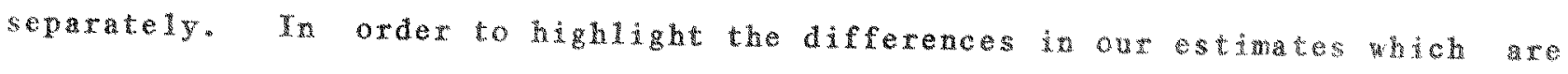
due to the estination method axd those which are due co the wse of

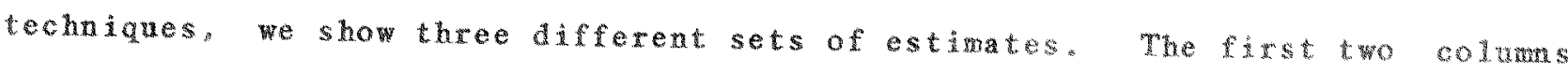

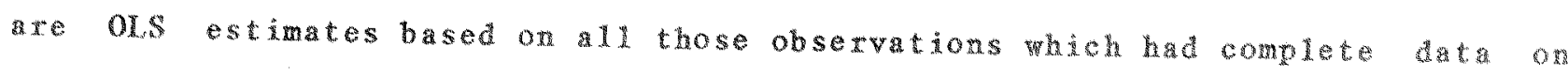

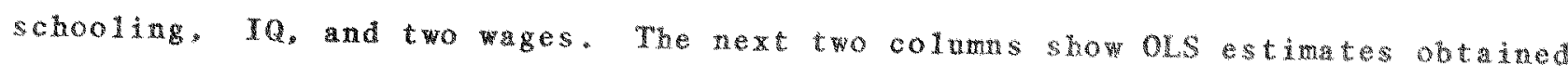

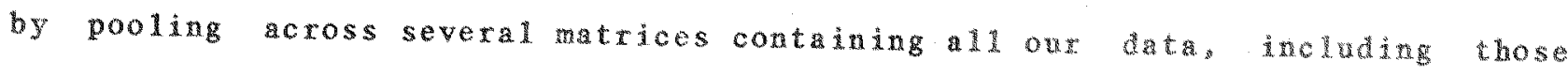
observations which are missing 10 and/or one or more wages. phe point estimntes do not chage that mach, and the standard exors go down by abont twetry or

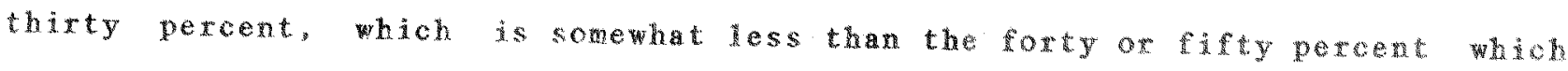

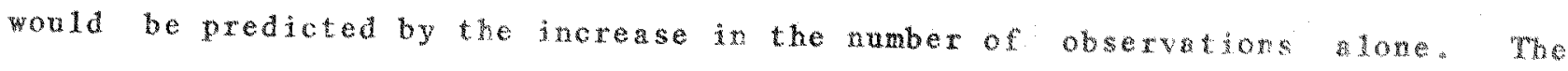

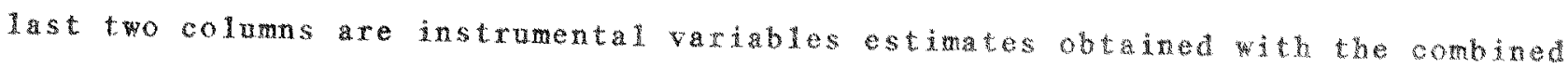

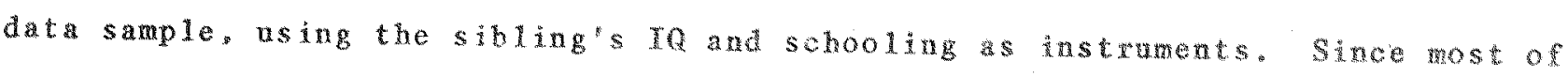

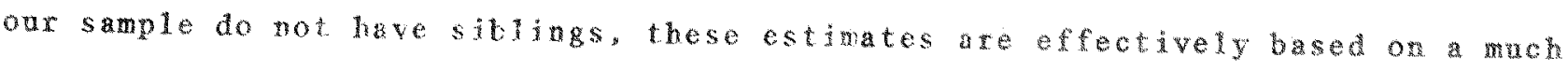
smaller number than the number of observations show in the tablo

The OLS estimates of the schooling coeffiobents are retatioly dow but 
when they are combined with the age coefficient from the reduced form regression, we obtain more conventional estimates, .061 and .059 for males and 0.096 and .069 for females, similar to those already in the literature (see Shackett, 1981, and Sande11 and Shapiro, 1974, among others). Instrumenting both schooling and IQ raises the schooling coefficient by as much as four or five percent in rate of return units but at the price of much larger standard errors on both coefficients, due both to the reduction in effective sample size and the usual increase from IV.

Table 4 gives the correlation matrices for our main variables (net of the previously swept out exogenous variables) for our combined data siblings sample, showing both the individual correlations and the cross-sib ones. These matrices are pairwise combinations of the set of 24 matrices for which we obtain maximum likelihood estimates in Table 5. Taking LW2 as the variable of primary interest, the observed cross-sib wage correlations are quite low: .11,.34, and 0.07 for brother, sister, and brother-sister pairs, respectively. While the genera 1 pattern is similar to that observed earlier by Shackett, $(.18, .22$, and $0.00)$, we find less of a contrast between same sex and opposite sex cross-sib correlations. The pattern in the male and fenale matrices appears to be very similar, except for somewhat higher correlations for the females and correspondingly higher variances for the males. In fact, the covariance matrices appear more similar than the correlation matrices. The other difference which can be seen in this table is a higher ratio of individual to family variance for the men, a finding which is confirmed by our estimates later on (compare the diagonals of the two cross-sib matrices).

Table 5 gives the maximum likelihood estimates of our model on all of the available data for each of the sexes, based on the combination of data from 24 matrices. These matrices were created by considering two dinensions of "missing": missing data and missing siblings. First we have individuals that 
have (1) complete data on all variables, (2) are missing ro scores, (3) are missing wages, and (4) are missing both wages and ro scores. Second, we have three types of stblings (male, ferale, and opposite) with thatemg data wissing patterns and an extre watrix where only one wage of one sibling is missing. The intersection of these two dimensions yields nine matrices fox each sex and six for the male-female pairs. The actul astribution of the data across these

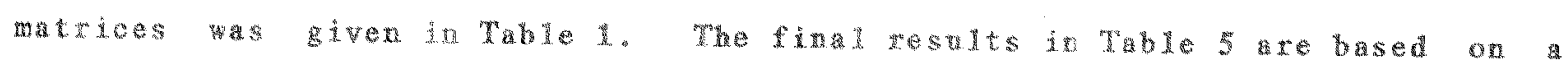
combindion of information from 579 sibling paixs and 3262 additional individuats for wales and 557 siblings and 4732 individuals for femalles.

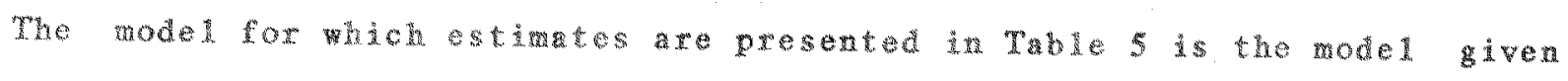
by equations (2)-(4) and wigure 1. with the addition of a second wage vaxiable. Since the coeficients on the wge variables are not constrained and there is a free cormelation between wages both whin individuals and across siblings, this additional wage variable imposes no new constraints on the model. brt merely provides another, later indicator of the indididul's lifetime income. In estimating this thodel in th most general form, we wlowed both for different (correlated) fense and male factors and fow diffexent loading on these factors across the sexes. The estimated correlations for the two factors were 0.97 $(.07)$ and $0.90(.16)$ fot the ability and wealth factors respectively and the $x^{2}(2)$ statistic for a cortalation of unity across male and female factors was 0.8: accordingly. we have constrained the factors, but not the factor loadings, to be the same in the results presented. The estimates of the other parameters are not affected matexially by this constraint.

The first part of the table gives the estimated coeficients. standad extors, and residual variances while the second part lists the estimated covatiances across equations and across siblings. The final panel in this table shows 1 so tho estinated wage covariances for the cross-sib pairs. The method 
of estimation was maximum likelihood and the standarderrors reported are the conventional estimates.

There are a number of remarks about these results: (1) The estimated factor loadings for both unobservable factors, A and W, are quantitatively and statistically very similar for males and females $\left(X^{2}(5)-6,6\right)$. The estimated taus (the ratio of individual to family variance components of the ability factor) do seem to be different, implying a higher overall contribution of the ability factor to male success, but also, simultaneously, a relative larger role of the family component for women in this story. These differences, however, are only marginally significant, with an estimated t statistic of 1.5 .

(2) The role of the "ability" factor in the wage equation is marginal, both in the sense that its coefficients are not significantly different frow zero and in the sense that it contributes little to the explanation of the variance of wages. In fact, the model in general adds 1 ittle (about .01 out of 0.15) to the explanation of the variance of wages once we have swept out the exogenous variables.

(3) The schooling coefficients are not estimated very precisely. If the relevant age coefficients from Appendix B are added to them, the resulting estimates are $0.094,0.063$ and $0.122,0.069$ for LW1, LW 2 , and males and fema 1 es respectively. In spite of the fact that the contribution of the "ability" factor in the wage equation is not wel1 defined, it appears to be multicollinear with schooling, with the schooling coefficients falling when the estimated factor coefficients are higher. This basic result is the sane as what we saw in the OLS-IV contrast in Table 3 : using the sibling's IQ and schooling as instruments increases the estimated schooling coefficient but also greatly increases the standarderrors on both IQ and schooling since the parts of IQ and schooling which are correlated with the sibling variables are morecollinear in the wage equation. 
(4) There is no significant pattern in the residual covariances reported in the second part of Table 5 except for the own serial correlation between early and late wages. which is estimated at about 0.4 . Besides this, the only covariances which appear to be significant are those across the wage residuals of the same-sex siblings. This is the same effect we noted in the data in Table 4: in these estimates about half of the higher late wage covariance botween sisters is explained by the stronger famly component of the ability factor (both on its own in wages and via schooling) while the remainder appents in the differing estimates of the residual covariance (.025 versus .016). The difference between the estimated cross-sex wage covariance and the same-sex covariances has not been explatided by the ability-schooling components of these variances -w the estimated covariances are as far apart as in the original correlation matrix. Howevex, a test for the equality of the wage covariances across all the siblings is not rejected due to their small size and fairly large standard extors $\left(X^{2}(7)=6.8\right)$.

A1 of the tests based on estimates in Table 5 degend on the particular identifying restriction we chose (the second factor appearing only in the schooling equation and not in IO). We can ask, however, how many comon factors are needed to rationalize the cross-sib correlations independently of this restriction or any particular rotation. Depending on whether we include wages or xestrict attention to just ro and schooling, two or three comon family factors should be enough to fully rationalize the same sex cross-sib correlations, bot if there were sex-specific components of "ability". "wealta", of wages, we would expect to need more than these two or three to fit the brother-sister correlations. Again we find no indication of sex-specisic effects. Using the complete data subset only, two factors adequately explain the ro-schooling correlation $\left(X^{2}(3)=0.14\right)$ and three adequately explain the $I Q$, 
schooling, wage correlations $\left(X^{2}(6)=0.88\right.$ or 2.28 depending on whether we use early or late wages. Since by allowing free correlation of the wages across the siblings we have effectively allowed for a third family factor in the estimating mode1, the factor analysis results confirm our finding that the unobserved family factors may be treated as the same across male and female siblings.

Each of these approaches leads us to essentially the same conclusion. At least as far as the IQ-schooling nexus is concerned, the unobservables that we can estimate play similar roles in accounting for the observable data and appear to be the same constructs for males and females. Families and schools treat brothers and sisters symmetrically, as far as we can discern using the rather gross measures of $I Q$ scores and years of schooling completed.

The labor market story is somewhat different, however. We know already that the schooling, age, and race coefficients differ between males and females. Beyond that it is hard to discern other differences in returns to the unobservable, non-schooling and TQ related components of human capita1. There is a slight indication of such differences in the asymmetry of the cross-sex cross-sib correlations. A sister's IQ and schooling is more helpful in predicting her brother's wages than vice versa, implying that those components of female $I Q$ and schooling which are correlated with their brother's success in the labor market are less useful in predicting their own success. Nevertheless, these effects are sma11 and not very significant either by statistical or substantive criteria. A difference of 0.1 in correlation can account for 1 ittle of the overall variance in the difference between male and female experiences in the labor market. 


\section{Conclusion}

The main finding of this paper is that the family effects in the row schooling-wage relationship are essentially sex-blind. This result is particularily strong for the ro-schooling relationship, where the observed differences in the data can be accounted for by a bigher whin famly variance among men of the single unobserved ability factor. Although we are also able to accept equality of the unobserved factors when fitting the wage equations, conclusions here are much less robust since most of the systematic variation in wages is taken out when exogenous factors are controlled for and our model is able to explain very little of the remaining variance. One of the other questions this paper was designed to answer was whether we could gain precision in our estimates of sibling models by using missing data techniques. In comparing estimates on the complete data (which are given in Appendix A) to those based on the combined sample of 24 matrices containing roughy four times as many observations, we find that the standard erros did go down in many cases by a factor of two. However, for some crucial parameters such as the wage covariances, they did not go down at a11. This, of course, should not be too surprising since the wage covariances are free and information on othex components of the model should not really help in estimating them. The lesson is that the technology helps only when we have extra data with information on the parameters of interest.

On the substantive issue that notivated this work. Whether ability is priced differently in the marketplace for mex and women. we have been able to say very little. There are two sources of the problem: (1) kage correlations across the siblings are very important for answering this question and we love relatively few wage pairs in these data. (2) It is difficult for us to 
differentiate between the sexes using test scores, since we have on 1 y one indicator of ability, To, and in designing that indicator attempts were made to minimize the apparance of sex differences. An interesting extension of this work might be to apply this framework to a sample with a variety of test scores, 7 such as the recent Figl School and Beyond surveys (NORC, 1980) a1though the within person correlation could be aroblem when all tests are of the academic variety; that is, there may be little additional information in them.

Fina1ly, we remind the reader again that the mean wage for the men aged 27 in this dataset is forty per cent higher than the mean wage for women of the same age and that this difference is anaccounted for by anything reported in this paper. The mean $I Q$ and schooling level for the same men and women are equal, and our results indicate that they are getting the same returns from these factors. The cause of the discrepancy must be looked for elsewhere. 
Figure 1

Expected Variances and Covariances Implied by the Model in Equations 2-4

IQ $\quad$ S IW

Individual

$I Q$

$$
\gamma_{1}^{2}(1+\tau)+\sigma_{1}^{2}
$$

$Y_{1} \gamma_{2}(1+\tau)$

$Y_{1}\left(B \gamma_{2}+Y_{3}\right)(1+\tau)$

8

$\gamma_{2}^{2}(1+\tau)+n^{2}+\sigma_{2}^{2} \quad \gamma_{2}\left(\beta \gamma_{2}+\gamma_{3}\right)(1+\tau)+\beta n^{2}+\sigma_{23}$

ISW

$$
\left(\beta \gamma_{2}+\gamma_{3}\right)^{2}(1+\tau)+\beta^{2}\left(\eta^{2}+\sigma_{2}^{2}\right)+\sigma_{3}^{2}+2 \beta \sigma_{23}
$$

Cross-sibs (same sex)

IQ

$$
\gamma_{1}^{2}
$$

$\gamma_{1} \gamma_{2}$

$\gamma_{1}\left(\beta \gamma_{2}+\gamma_{3}\right)$

8

$r_{2}^{2}+n^{2}$

$\gamma_{2}\left(\beta \gamma_{2}+\gamma_{3}\right)+\beta n^{2}$

LW

$$
\left(\beta \gamma_{2}+\gamma_{3}\right)^{2}+\beta^{2} \eta^{2}+o_{3 a b}
$$

Cross-Sex Cross-Sib (male down versus female across)

Q

$$
\begin{array}{lcc}
\gamma_{I m} \gamma_{I f} \rho_{A} & \gamma_{1 m} \gamma_{2 f} \rho_{A} & \gamma_{I m}\left(\beta_{f} \gamma_{2 f}+\gamma_{B f}\right) \rho_{A} \\
\gamma_{I f} \gamma_{2 m} \rho_{A} & \gamma_{2 f} \gamma_{2 m} \rho_{A}+\eta_{f} \eta_{m} \rho_{W} & \gamma_{2 m}\left(\beta_{f} \gamma_{2 f}+\gamma_{3 f} \rho_{A}+\beta_{f} \eta_{f} \eta_{m} \rho_{W}\right.
\end{array}
$$


Table 1

Data Availability

\begin{tabular}{|lcllll}
\hline & $\begin{array}{c}\text { Young } \\
\text { Men }\end{array}$ & $\begin{array}{l}\text { Young } \\
\text { Women }\end{array}$ & $\begin{array}{l}\text { Brother Sister } \\
\text { Sample }\end{array}$ & $\begin{array}{l}\text { Sibs } \\
\text { Sample }\end{array}$ \\
\hline Sample \\
\hline Original sample & 5225 & 5159 & 1499 & 1464 & 3042 \\
\hline With good schooling & 4901 & 5027 & 1402 & 1410 & 2906 \\
\hline And good IQ & 3131 & 3149 & 885 & 874 & 1737 \\
\hline And an early wage & 4291 & 4060 & 1253 & 1162 & 2498 \\
\hline And both wages & 3110 & 2876 & 909 & 814 & 1728 \\
\hline And both wages and IQ & 2098 & 2016 & 594 & 562 & 1134 \\
\hline
\end{tabular}

Data Arrangement for Estimation

\begin{tabular}{|c|c|c|c|c|c|}
\hline & \multicolumn{3}{|c|}{ Pairs } & \multicolumn{2}{|c|}{ Individuals } \\
\hline & Brother & Sister & Sibs & Men & Women \\
\hline Complete data & 164 & 151 & 204 & 1616 & 1604 \\
\hline Missing IQ & 127 & 101 & 119 & 892 & 792 \\
\hline Missing wages for a male & 103 & & 59 & 232 & \\
\hline Missing wages for a female & & 107 & 87 & & 278 \\
\hline Missing wages for both & 38 & 40 & 48 & & \\
\hline Residua 1 & 147 & 158 & 257 & 112 & 167 \\
\hline
\end{tabular}

Note: Ce11 counts are the number of sibling pairs, or number of individuals in the case of the 1 ast two columns. Individuals cecur only once, but families occasionally occur more than once (ove percent in sibling samples, three percent in total sample). The slight discrepancies in observations counts between the top and bottom panels are due to the fact that the bottom pane 1 observations were also required to have good data on the KWW test score. 
Table 2

Summary Statistics

Young Men

Young Women

\begin{tabular}{|c|c|c|c|c|c|c|}
\hline Variable & Number & Me an & $\begin{array}{l}\text { Standard } \\
\text { Deviation }\end{array}$ & Number & Mean & $\begin{array}{l}\text { Standata } \\
\text { Deviation }\end{array}$ \\
\hline$L W 2$ & 3110 & 6.18 & 0.49 & 2876 & 5.78 & 0.44 \\
\hline LW1 & 4291 & 5.70 & 0.54 & 4059 & 5.46 & 0.44 \\
\hline $\mathrm{SC}$ & 4783 & 12.8 & 2.75 & 4728 & 12.6 & 2.41 \\
\hline IQ & 3131 & 101.4 & 15.9 & 3149 & 102.3 & 15.2 \\
\hline WHITE & 4783 & 0.72 & 0.45 & 4729 & 0.71 & 0.45 \\
\hline AGE6 8 & 4783 & 18.2 & 3.2 & 4729 & 18.8 & 3.1 \\
\hline REG68 & 4783 & 0.41 & 0.49 & 4729 & 0.32 & 0.47 \\
\hline AGE1 & 4291 & 22.6 & 2.9 & 4060 & 23.0 & 2.8 \\
\hline SMSA1 & 4291 & 0.71 & 0.45 & 4060 & 0.78 & 0.42 \\
\hline REG1 & 4291 & 0.39 & 0.49 & 4060 & 0.32 & 0.47 \\
\hline YEAR1 & 4291 & 70.6 & 3.6 & 4060 & 72.2 & 3.0 \\
\hline MAR1 & $4 ? 51$ & 0.48 & 0.50 & 3396 & 0.56 & 0.50 \\
\hline AGE2 & 3110 & 27.1 & 1.5 & 2876 & 27.0 & 2.0 \\
\hline SMSA2 & 4783 & 0.46 & 0.50 & 4729 & 0.61 & 0.49 \\
\hline REG2 & 4783 & 0.26 & 0.44 & 4729 & 0.20 & 0.40 \\
\hline YEAR2 & 3110 & 75.1 & 3.2 & 2876 & 75.8 & 2.3 \\
\hline MAR2 & 3047 & 0.67 & 0.47 & 2279 & 0.66 & 0.48 \\
\hline
\end{tabular}

Variable definitions:

LW1 - an early measure of $\log$ hourly earnings.

LW2 - a late measure of $10 \mathrm{~g}$ hourly earnings.

SC - years of schooling completed.

IQ - IQ test score.

WHTTE- dummy variable, 1 if respondent is white.

AGE - Age in years (at the time of early or late wage).

SMSA - dummy variable, 1 if respondent lives in SMSA.

REG - dummy variable, 1 if respondent lives in the South.

YEAR - calendar year corresponding to early or late wage.

MAR - dummy variable, 1 if respondent married, spouse present.

(This variable was not swept out in reduced form regressions).

Warning: The means for variables indexed with $1^{\prime}$ 's and $2^{\prime} s$ were taken over those with early or late wages respectively. The changes in these variables should not therefore be interpreted as changes in the underlying population. 
Table 3

\section{Individua 1 Earnings Equations}

Men

\begin{tabular}{|c|c|c|c|c|c|c|}
\hline & \multicolumn{2}{|c|}{ OLS } & \multicolumn{2}{|c|}{$\begin{array}{l}\text { OLS with } \\
\text { Missing Data }\end{array}$} & \multicolumn{2}{|c|}{$\begin{array}{c}\text { Instrumental } \\
\text { Variables }\end{array}$} \\
\hline & $\mathrm{LW}_{1}$ & $\mathrm{LW}_{2}$ & $\mathrm{LW}_{1}$ & $\mathrm{LW}_{2}$ & $\mathrm{LW}_{1}$ & $\mathrm{LW}_{2}$ \\
\hline sc & $\begin{array}{l}.007 \\
(.004)\end{array}$ & $\begin{array}{l}.023 \\
(.004)\end{array}$ & $\begin{array}{l}.017 \\
(.003)\end{array}$ & $\begin{array}{l}.030 \\
(.003)\end{array}$ & $\begin{array}{r}.054 \\
(.011)\end{array}$ & $\begin{array}{l}.043 \\
(.011)\end{array}$ \\
\hline IQ & .0013 & .0026 & .0006 & .0019 & -.0066 & -.0013 \\
\hline$\sigma^{2}$ & $\begin{array}{c}(.0007) \\
.143\end{array}$ & $\begin{array}{c}(.0007) \\
.151\end{array}$ & $\begin{array}{c}(.0006) \\
.149\end{array}$ & $\begin{array}{c}(.0006) \\
.153\end{array}$ & $\begin{array}{c}(.0016) \\
.157\end{array}$ & $\begin{array}{l}(.0016) \\
.154\end{array}$ \\
\hline Number & 2148 & 2148 & 4784 & 4784 & 4784 & 4784 \\
\hline
\end{tabular}

Women

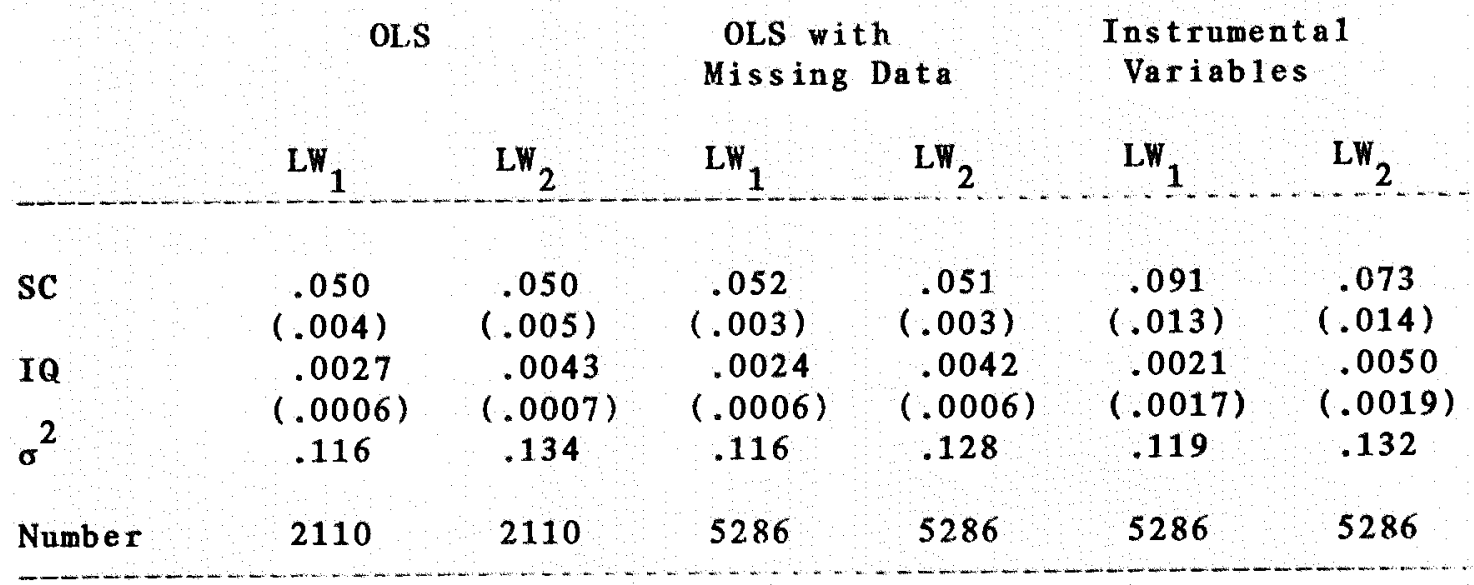

Note: All equations were estimated on the residuals from equations which included age, urban and sonthern residence, race, and year dummies (in the case of wages). The number of observations shown is the total number used for estination in that column. 
Table 4

Correlation Matrices of Residuals from Reduced

Form Equations: Pairwise Available Data

Individua 1

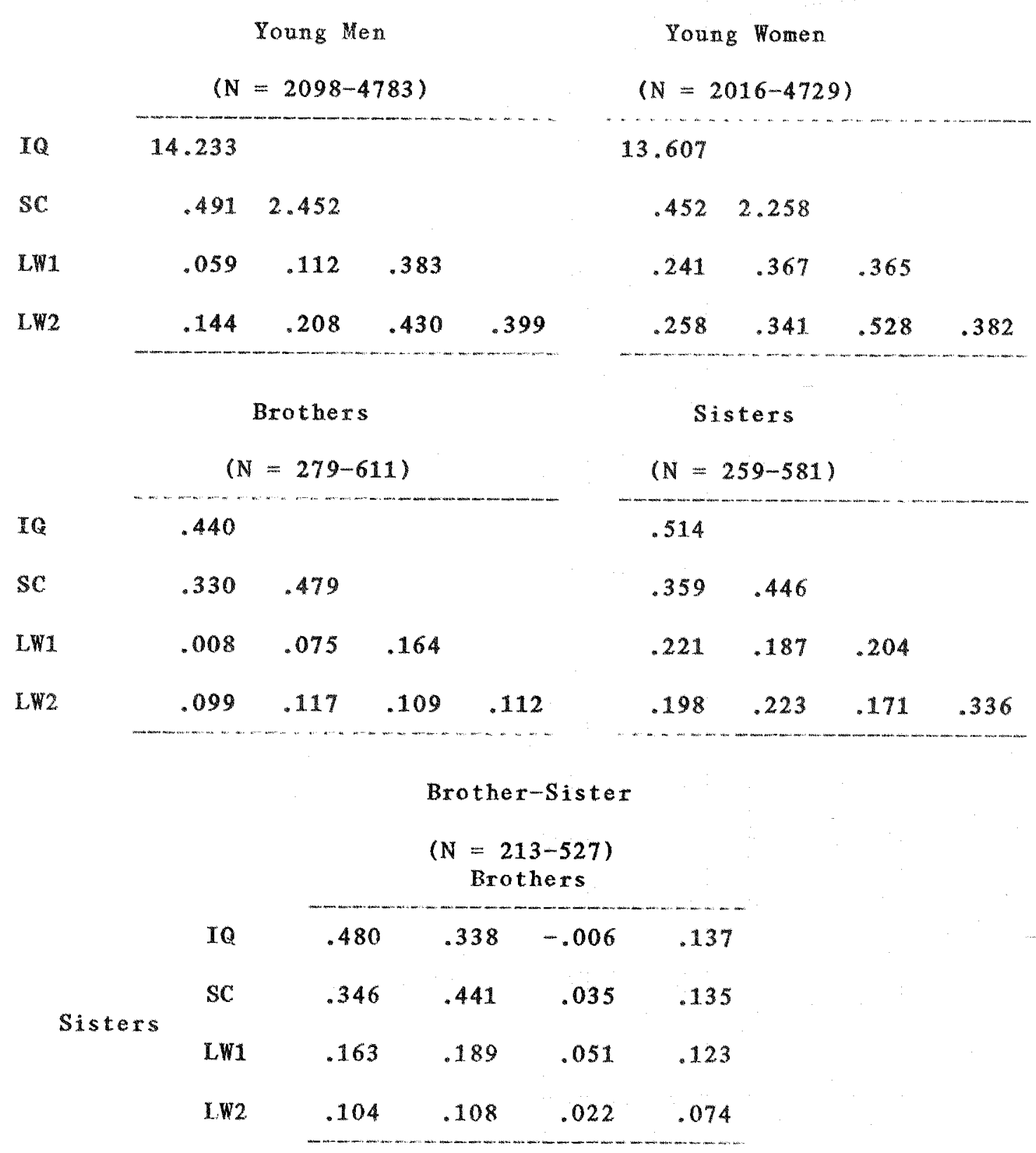

Note: All variables are residuals from regressions reported in Appendix 3 which sweep our exogenons variables, such as race and age. Numbers on diagonals in uppermost panels are standard deviations. Correlations are computed over all available pairs, or individuals. 
Tab1e 5

Joint Maximum Likelihood Estimates of the Fu11 Mode1

Young Men

\begin{tabular}{|c|c|c|c|c|c|c|c|c|}
\hline $\begin{array}{l}\text { Dep. } \\
\text { Var. }\end{array}$ & sc & A & W & $\sigma^{2}$ & SC & A & $W$ & $\sigma^{2}$ \\
\hline IQ & & $\begin{array}{r}9.86 \\
(0.42)\end{array}$ & & $\begin{array}{l}66.0 \\
(9.3)\end{array}$ & & $\begin{array}{r}9.72 \\
(0.39)\end{array}$ & & $\begin{array}{l}70.7 \\
(7.9)\end{array}$ \\
\hline SC & & $\begin{array}{c}1.28 \\
(0.08)\end{array}$ & $\begin{array}{l}1.16 \\
(0.09)\end{array}$ & $\begin{array}{c}2.29 \\
(0.18)\end{array}$ & & $\begin{array}{c}1.22 \\
(0.07)\end{array}$ & $\begin{array}{c}0.94 \\
(0.09)\end{array}$ & $\begin{array}{c}2.38 \\
(0.15)\end{array}$ \\
\hline LW1 & $\begin{array}{l}.040 \\
(.019)\end{array}$ & $\begin{array}{r}-.016 \\
(.027)\end{array}$ & & $\begin{array}{c}0.15 \\
(.004)\end{array}$ & $\begin{array}{l}.076 \\
(.023)\end{array}$ & $\begin{array}{r}.013 \\
(.030)\end{array}$ & & $\begin{array}{c}0.11 \\
(.003)\end{array}$ \\
\hline LW2 & $\begin{array}{l}.027 \\
(.019)\end{array}$ & $\begin{array}{r}.034 \\
(.027)\end{array}$ & & $\begin{array}{l}0.15 \\
(.004)\end{array}$ & $\begin{array}{l}.050 \\
(.024)\end{array}$ & $\begin{array}{r}.060 \\
(.032)\end{array}$ & & $\begin{array}{l}0.13 \\
(.004)\end{array}$ \\
\hline
\end{tabular}

Estimated Covariances

Individua 1 Sibling Individua $1 \quad$ Sibling

SC LW1 LW2 LW1 LW2 SC LW1 LW2 LW1 LW2

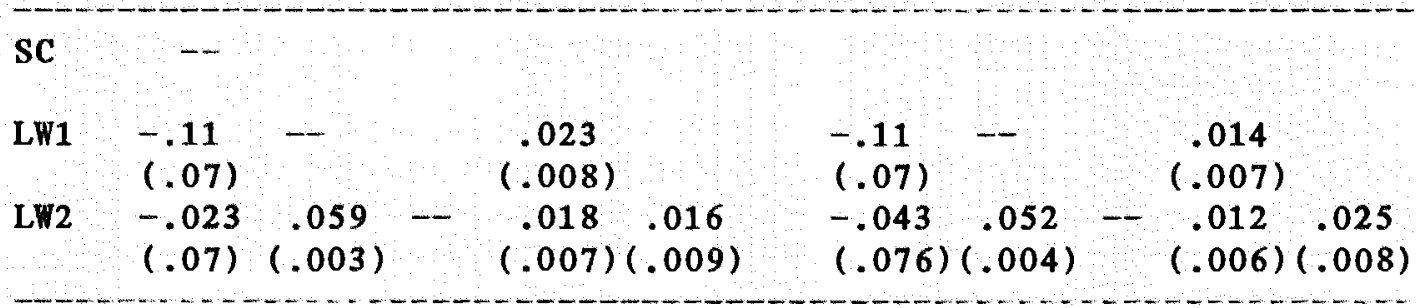

Estimated Covariances Across Sexes

\begin{tabular}{|c|c|c|c|}
\hline & \multicolumn{2}{|c|}{ Fema $1 \mathrm{e}$} \\
\hline & & LW1 & LW2 \\
\hline & LW1 & $\begin{array}{c}.011 \\
(.008)\end{array}$ & $\begin{array}{r}.003 \\
(.008)\end{array}$ \\
\hline Ma $1 \mathrm{e}$ & $\mathrm{LW} 2$ & $\begin{array}{r}.005 \\
(.008)\end{array}$ & $\begin{array}{l}.001 \\
(.008)\end{array}$ \\
\hline
\end{tabular}

Log Like 1 ihood $=-22,129.2$

* These, estimates are based on the constraint that $\rho_{0}=\rho_{\text {. }}=1.0$;

the $x^{2}$ (2) for equality of the male and female factors $=0.8$. 
1. An earlier version of this paper was presented at the Conference on the Economics of the Family, University of Pennsylvania, Apri1 12-13, 1984. We are grateful to the conference participants for comments and to Mark Watson for helpful discussions. We are also indebted to NSF Grant S0C78-04279 for financial support, to Ted Shi for research assistance, and to Sumanth Adanki and clint Cummins for assistance with the computation.

2. If we were to a11ow $\mathrm{u}_{1}$ and $\mathbf{u}_{3}$ to be freely correlated, the model would be exactly identified. The restriction that $\mathrm{Eu}_{1 \mathrm{~A}} \mathrm{u}_{3 \mathrm{~A}}=\mathrm{Eu}_{1 \mathrm{~B}^{\mathrm{u}}} \mathrm{B}_{\mathrm{B}}=0$, $\hat{i}_{0} \mathrm{e}$, that this covariance is fully captured by the variance component $\mathrm{B}$. is in the spirit of IQ being an error ridden measurement of ability, but is not essential for identification.

3. These "IQ test scores" are in fact from a variety of intelligence tests collected by the high schools and rescaled to standard IQ units by the NLS.

4. Less than one percent of families occur twice among the sib data and less than three percent of unmatched individuals actually have a sib in the sib data.

5. Necessary conditions axe given in Macurdy 1981. Basically the first and second partials of the model must be uniformly continuous and possess finite first and second moments.

6. Data which is not missing randomly may also change the variances and distributions of the observed data. This can be accomodated in estimation by (1) allowing the estimated variances of the unobservables to vary with the samples and (2) by computing robust standard errors for the model. Neither of these have been done in the current version of the paper but we plan to do so in the future.

7. The standard attack, in this context, on the missing data problem, would be to compute a correlation matrix based on pairwise complete data and then base estimates on that. As long as data is missing at random this method should be consistent, but it suffers from two drawbacks. The standard errors computed ignoring the differential data availability will be nonsense. Furthermore the maximum-1ikelihood technique shades naturally into estimation that at least partially models the sample generating mechanism and is thus robust to a certain amount of non-randomness.

8. A 1ater version of this paper will contain estimates of the standard errors which are robust to nonnormality of the data. 
9. The National Longitudina1 Surveys of Young Men and Women also contain scores on a "Knowledge of the World of Work" test which we originally planned to use in this study. Unfortunately, the tests themselves were not the same across the two sexes so that they could not be used as an indicator variable which would provide additional identifying power. We therefore decided not to use these scores in the final version of the model. 


\section{References}

A11ison, P.D., Maximum Likelihood Estimation in Linear Models When Data Are Missing." Revised version of a paper presented at the 1981 Annual Meeting of the American Sociological Association.

Becker,G.S., "The Allocation of Effort, Specific Human Capita1, and Sexual Differences in Earnings and the Allocation of Time, unpublished (1983).

Behrman, J.R., Z. Hrubec, P. Taubman and T.J. Wales, Socioeconomic Success: A Study of the Effects of Genetic Endowents, Family Environment, and Schooling (Amsterdam: North Holland, 1980).

Center for Homan Resonrce Research. The National Longitudinal Surrey Handbook (Columbus, Ohio: Ohio State University, 1979).

Chamberlain, G., "Omitted Variable Bias in Panel Data: Estimating the Returns to Schooling," in. The Econometrics of Panel Data, (Paris: Annales de 1'INSEE, No. 30/31, pp. 49-82, 1978).

and Z. Griliches, "Unobservables with a Variance-Components Structare: Ability. Schooling and the Economic Success of Brothers," International Economic Reviev 16(2) (1975).

"More on Brothers," in, P. Taubman, ed., Rinometrics: Determinants of Socioeconomic Success within and between Families (New York: North Ho11 and, 1977).

Griliches, Z., "Estimating the Returns to Schooling: Some Econometric Problems," Econometrica 45 (1977), 1-22.

- "Sib1ing Models and Data in Economics: Beginnings of a Survey," Journal of Political Economy 87(5), Part 2 (1979), \$37-\$64.

" Data Problems in Econometrics," in, M. Intriligator and Z. Griliches, eds., Handbook of Econometrics, Volume III (Amsterdan: North Ho11 and, forthcoming 1985).

- B.H. Ha11 and J.A. Hausman, "Missing Data and Self-Selection in Large Pane1s," Annales de L'INSEE No. 30-31 (1978).

Ha11, B.H., MOMENTS, the Moment Matrix Processor User Manue1, (Stanford, California: 1979).

Hauser, R.M. and R.N. Daymont, "Schooling, Ability and Earnings: CrossSectiona 1 Findings 8 to 14 Years After High School Graduation,"Soc. Educ. 50 (1977), 182-206.

Jencks, C., Who Gets Ahead? (New York: Basic Books, 1979). 
Joreskog, R.G, and D. Sorboun, LISREL: Analys is of Linear Structural Relationships by the Method of Maximum Likelihood (Chicago: National Resources, 1981).

Little, R.J.A., "Models for Non-Response in Sample Surveys," Journal of the American Statistical Association, 77 (378) (1982), 237-250.

Mincer, J., Schooling, Experience, and Earnings (New York: Columbia University Press for NBER, 1974).

and $\mathrm{J}$. Polachek, "Family Investments in Human Capita 1: Earnings of Women," Journal of Political Economy 82(2), Part II (1974), S76-S108.

NORC, High School and Beyond: A National Longitudinal Survey for the 1980's, (Chicago: NORC, 1980).

Rubin, D.B., "Inference and Missing Data," Biometrika 63(3) (1976), 581-592.

Sande11, S.H. and D. Shapiro, "The Theory of Human Capita 1 and the Earnings of Women: A Reexamination of the Evidence," Journal of Homan Resources 8 (1978), 103-117.

Scarr, S. and G. McAvay, "Predicting the Occupational Status of Young Adu1ts: A Longitudinal Study of Brothers and Sisters in Adoptive and Biologically Related Families," Department of Psychology, Yale University (unpublished, 1982).

Shackett, J.R., Experience and Earnings of Young Women, Ph.D. thesis, Harvard University (unpublished, 1981).

Smith, J.P., Female Labor Supply: Theory and Estimation (Princeton: Princeton University Press, 1980). 


\section{Appendix $\mathrm{C}$}

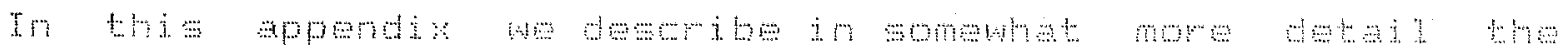

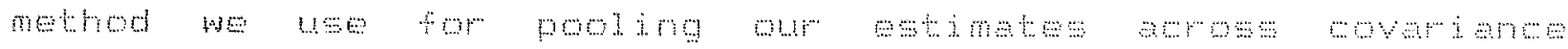

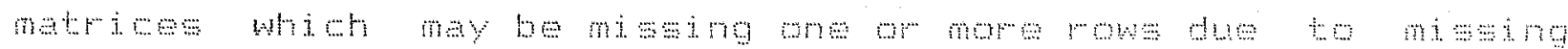

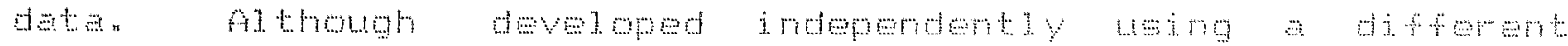

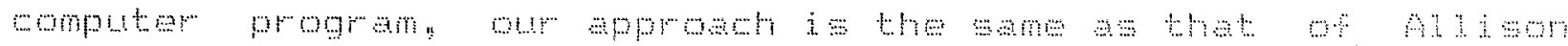

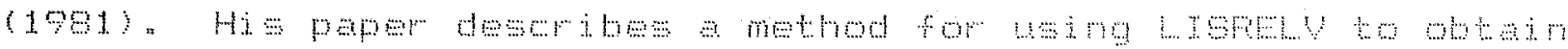

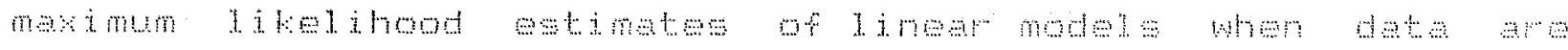

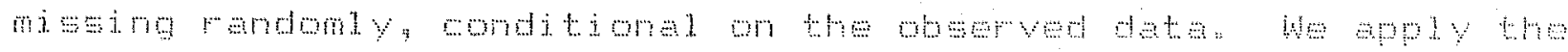

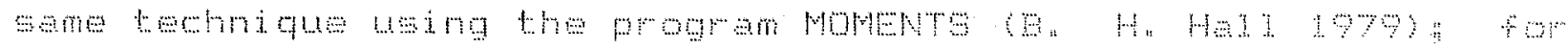

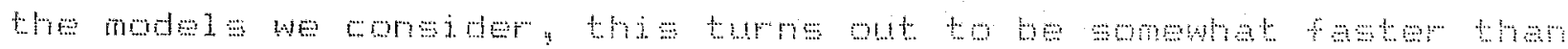

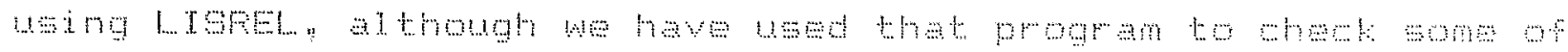
otim

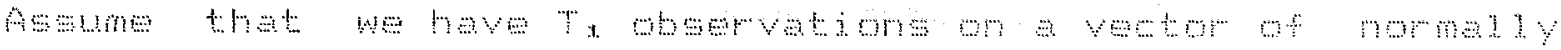

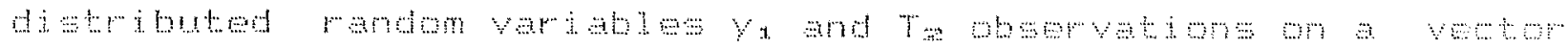

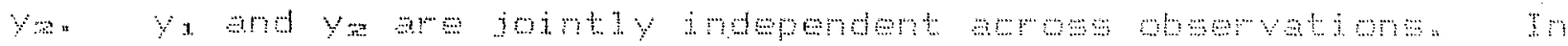

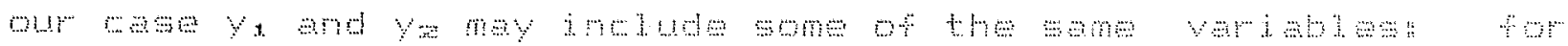

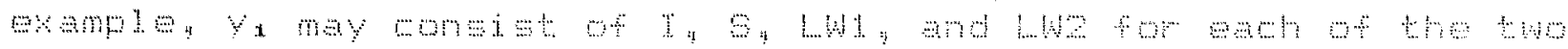

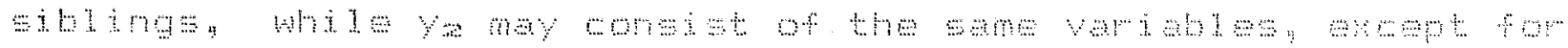

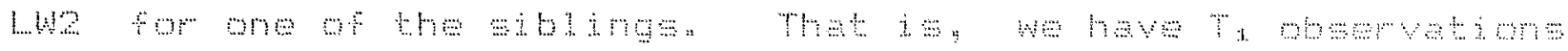

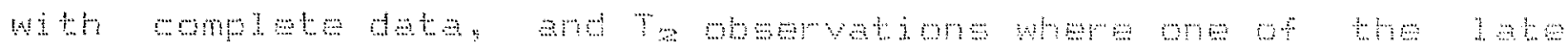

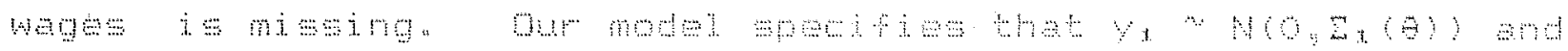

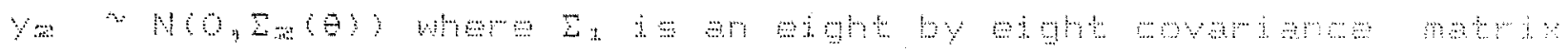

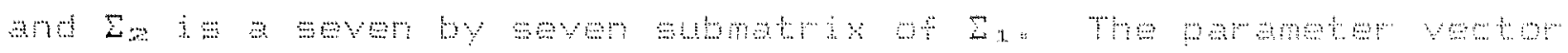

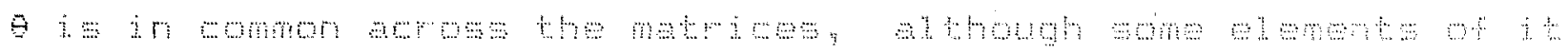




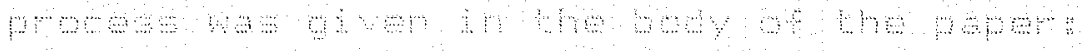

$$
\text { H } 1 \text { ( }
$$

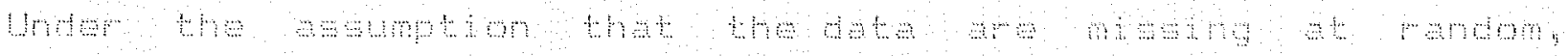
matminam ma

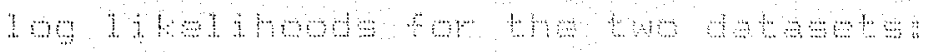

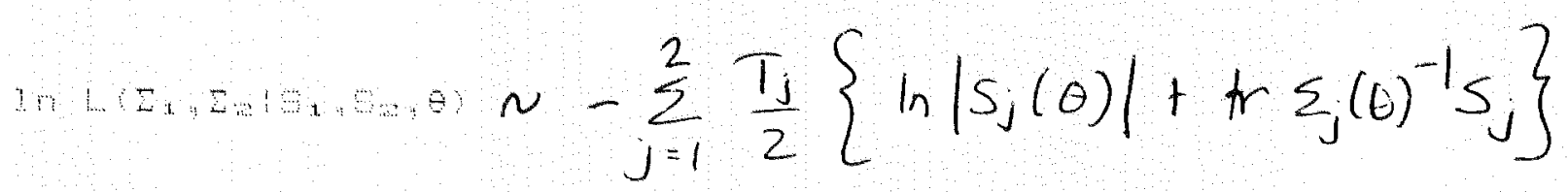

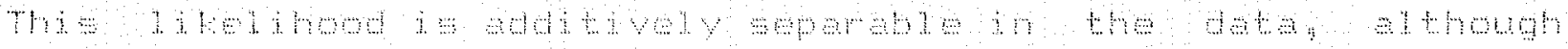
wm mom mo

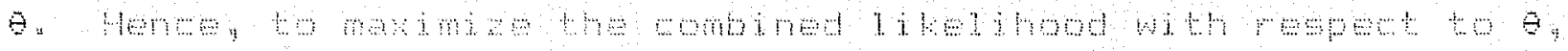

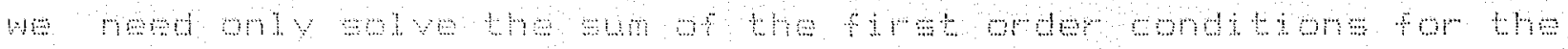
mor

$$
\frac{\partial \ln L}{\partial \theta_{i}}=\sum_{j=1}^{N}\left\{-\frac{T_{j}}{2} \operatorname{tr}\left[\left(I-S_{j} \Sigma_{j}(\theta)^{-1}\right) \frac{\partial \Sigma_{j}}{\partial \theta_{i}} \Sigma_{j}(\theta)^{-1}\right]\right\}=0 \forall i, L=1, j, k
$$

Ner the

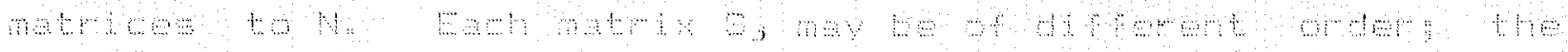

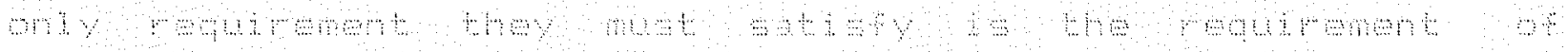

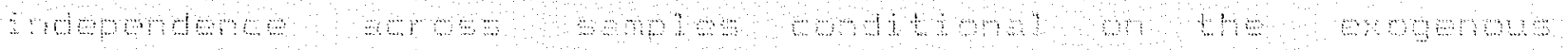
४

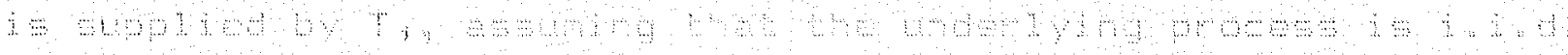
H

39 


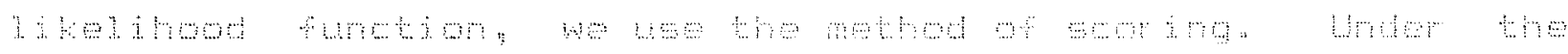
mus a y

$$
E \frac{\partial^{2} \ln L}{\partial \theta_{i} \partial \theta_{l}}=\sum_{j=1}^{N}\left\{-\frac{T_{j}}{2}+r\left[\frac{\partial \Sigma_{j}(\theta)}{\partial \theta_{l}} \Sigma_{j}(\theta)^{-1} \frac{\partial \Sigma_{j}(\theta)}{\partial \theta_{i}} \Sigma_{j}(\theta)^{-1}\right]\right\}
$$

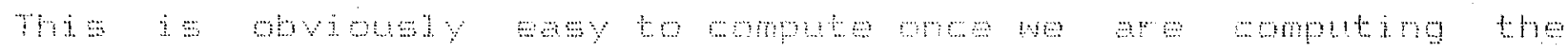

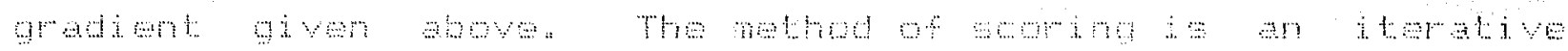

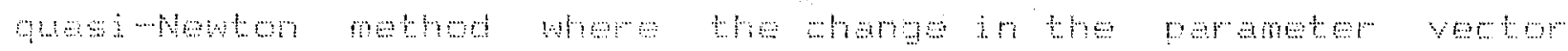

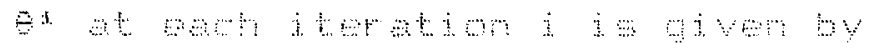

$$
\Delta \theta^{i}=\left.\left[\left.E \frac{\partial^{2} \ln L}{\partial \theta \partial \theta^{\prime}}\right|_{\theta^{i-1}}\right]^{-1} \frac{\partial \ln L}{\partial \theta}\right|_{\theta^{i-1}}
$$

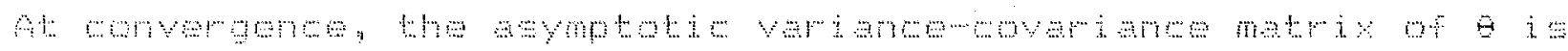

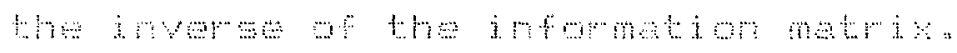

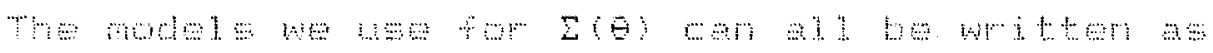

$$
A(\theta) y=B(\theta) \varepsilon
$$

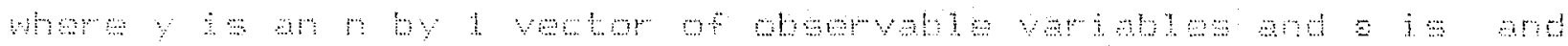

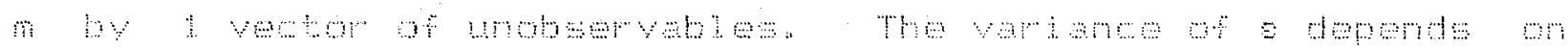

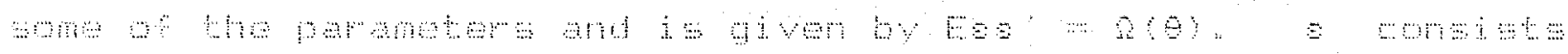

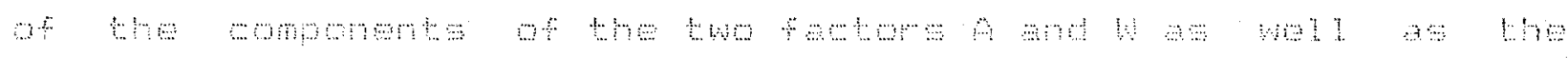
ваны

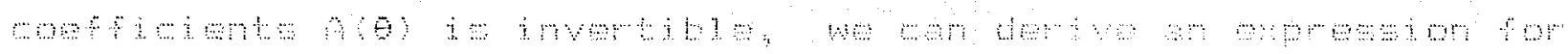

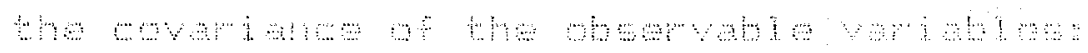

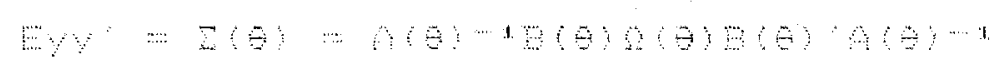




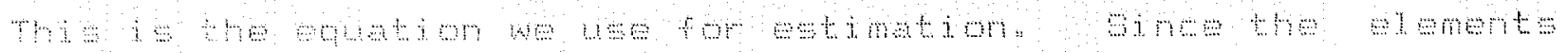

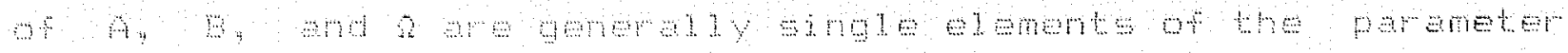

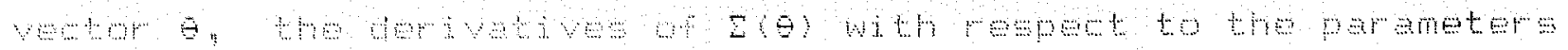

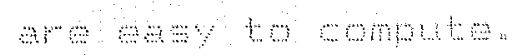

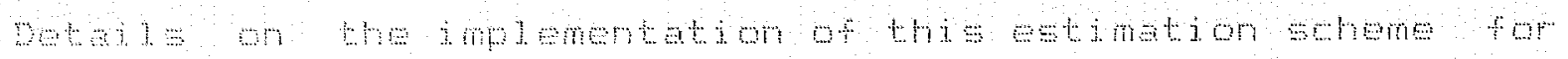

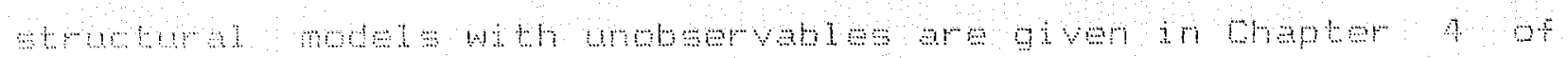

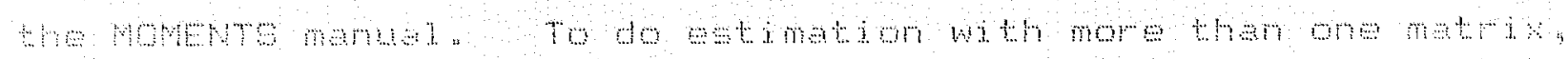

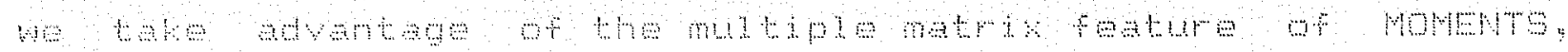

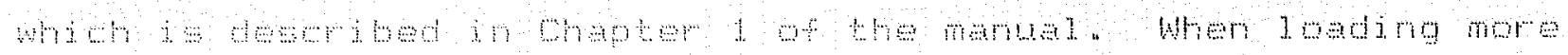

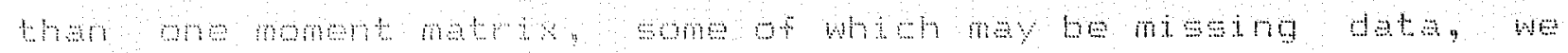

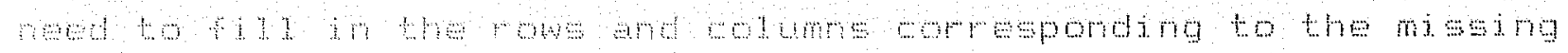

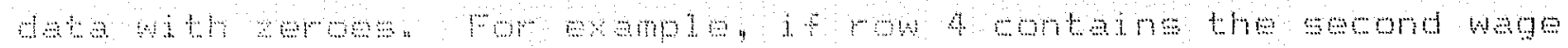

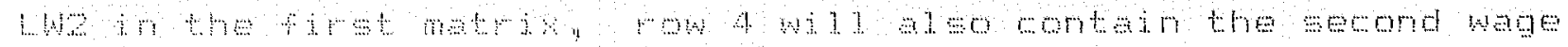

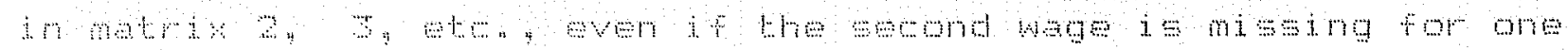

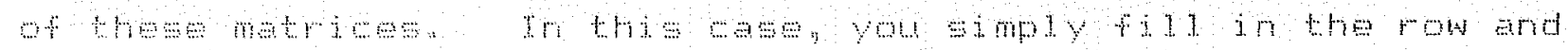

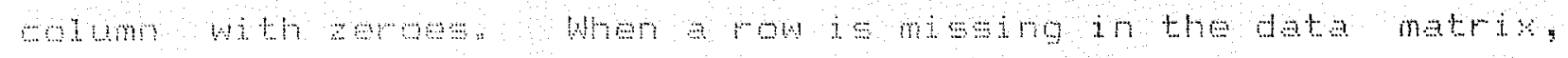

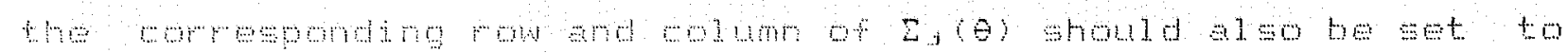

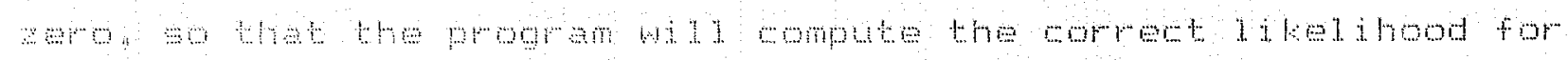

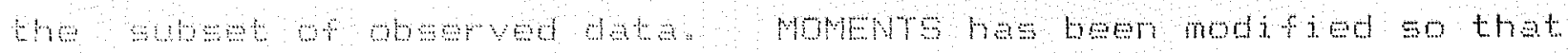

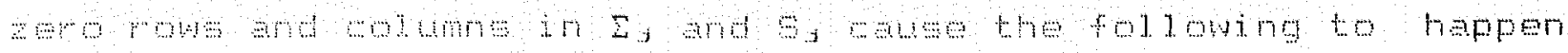

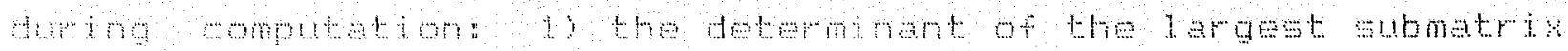

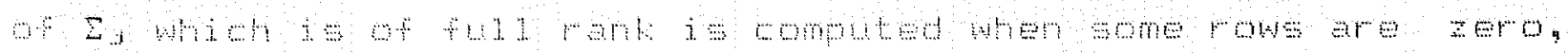

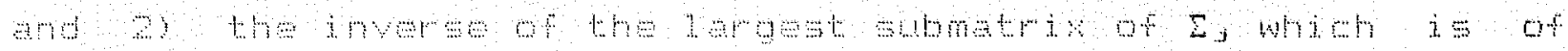

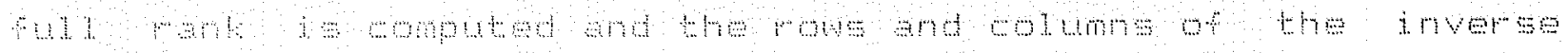

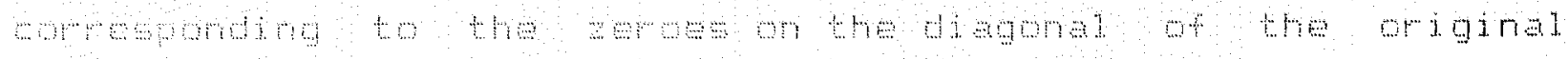

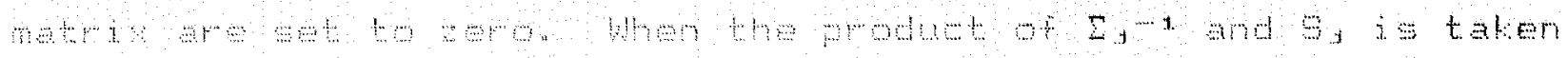

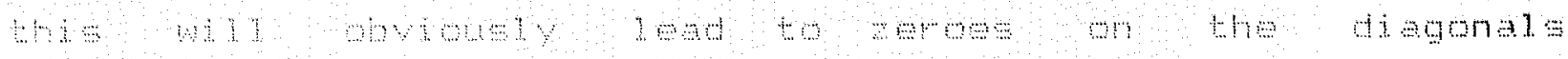




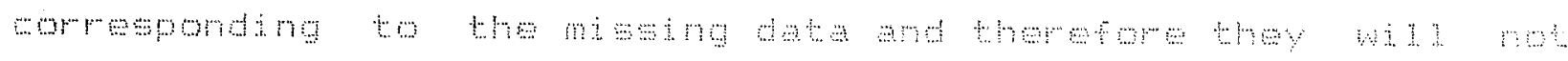

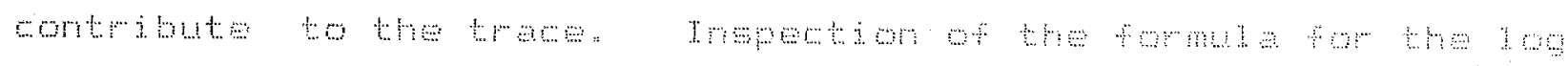

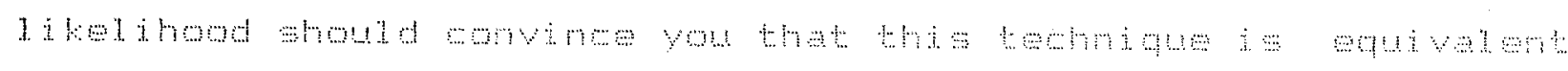

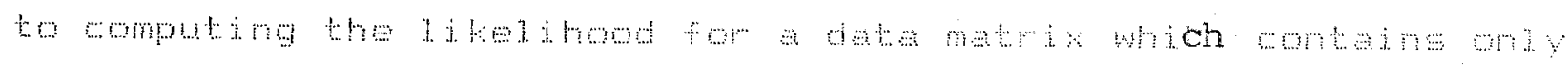

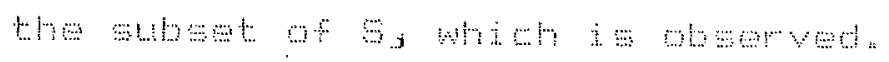

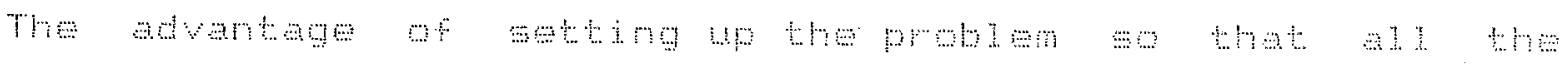

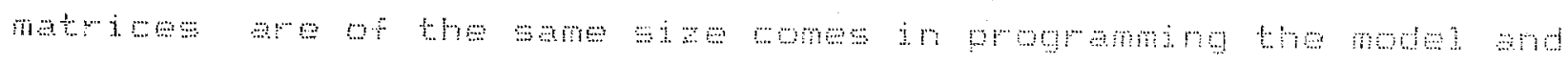

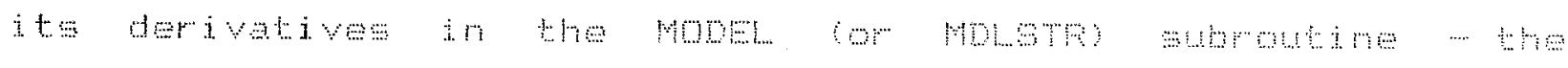

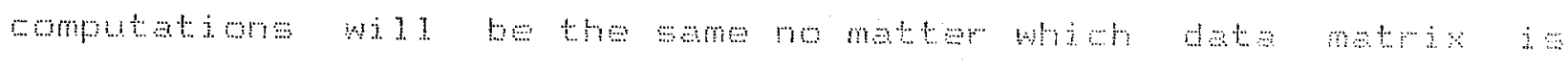

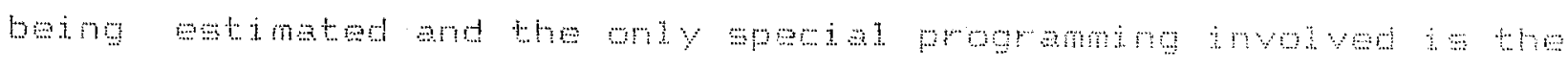

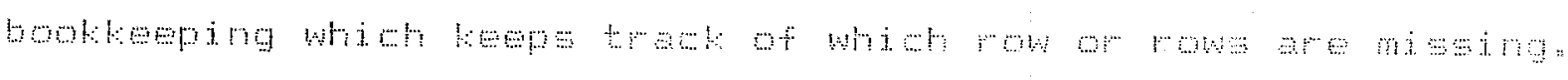

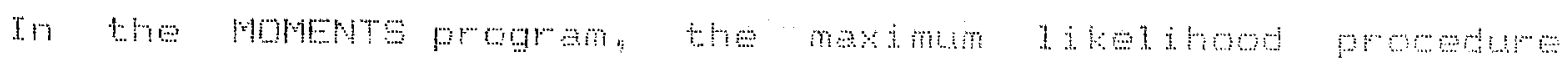

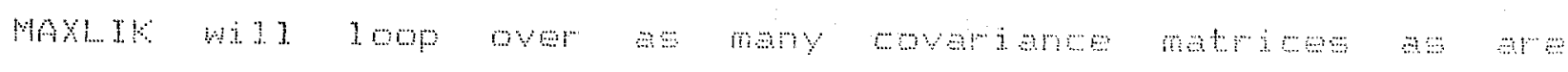

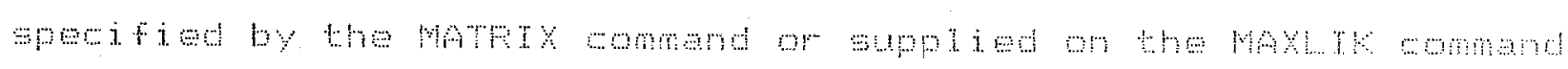
ifself

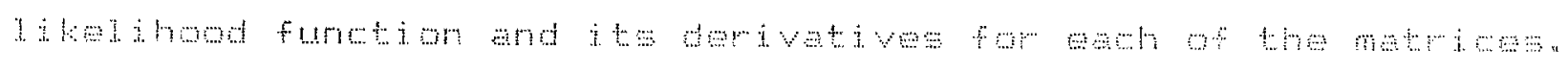

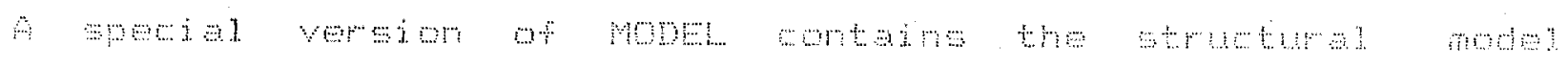

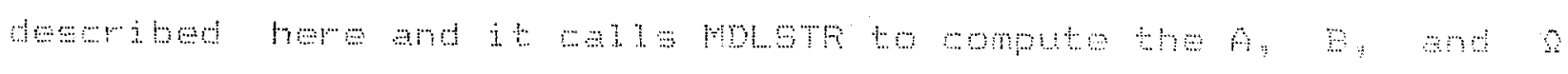

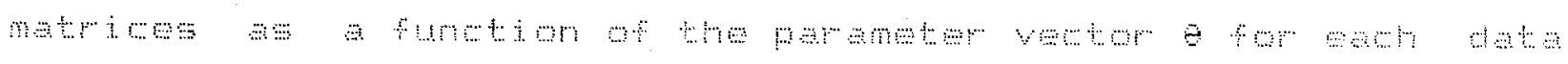

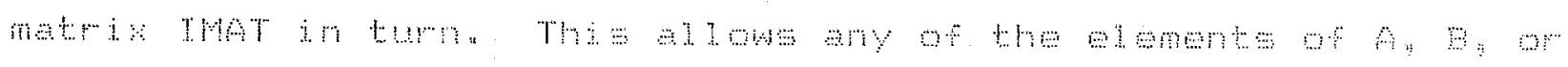

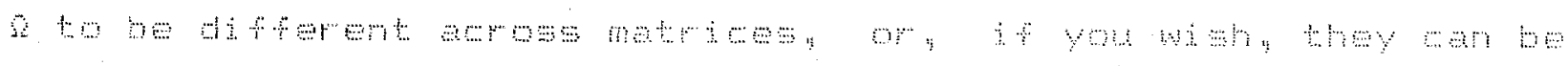

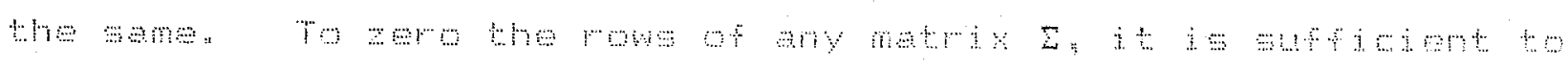

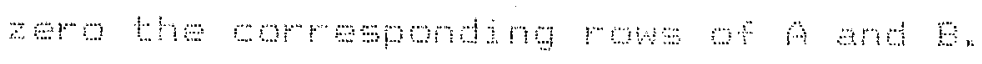




\section{Appendix D}

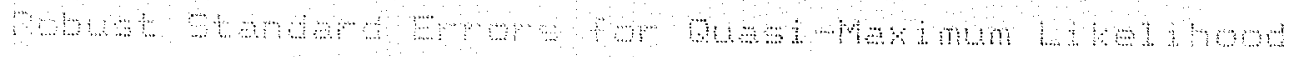

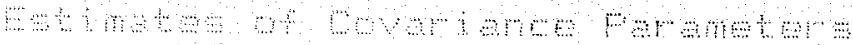

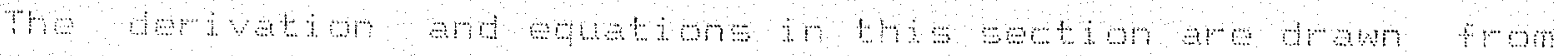

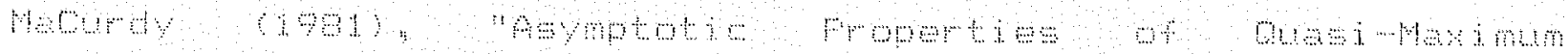

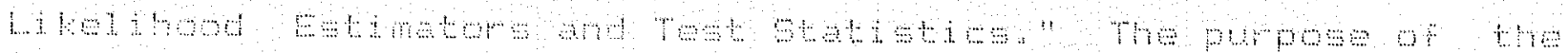

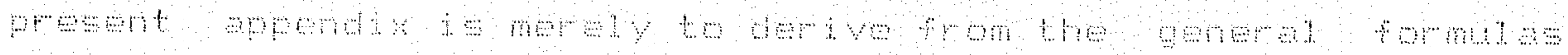

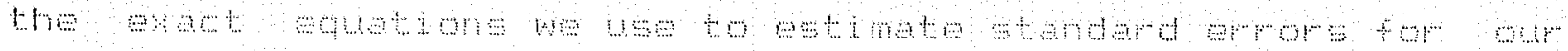
$\bmod 1$.

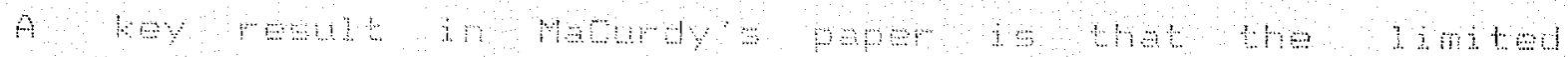

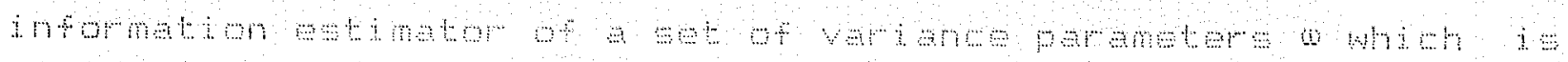

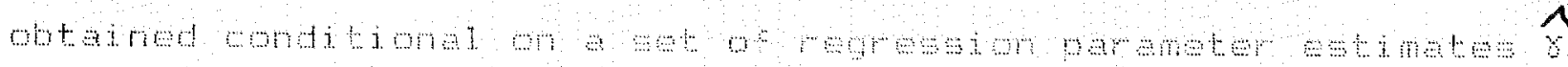

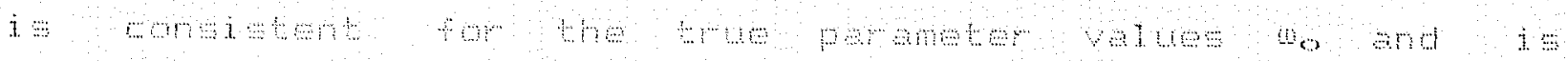

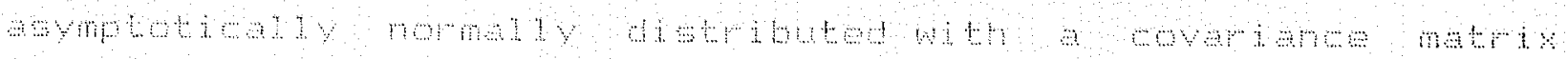

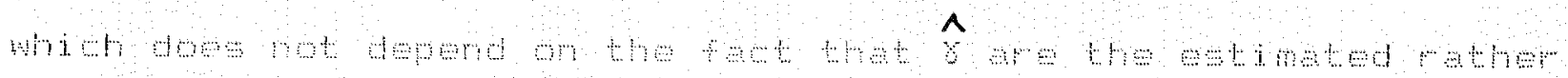

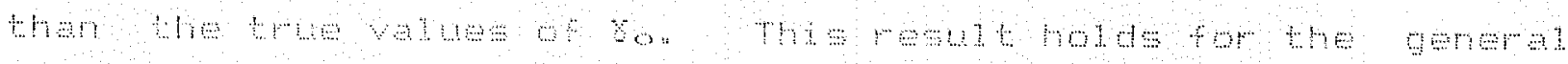

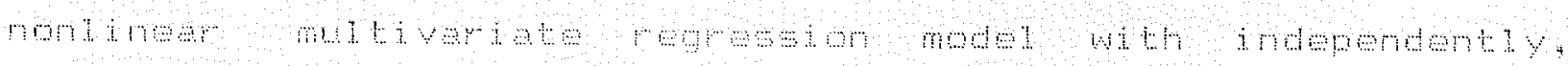

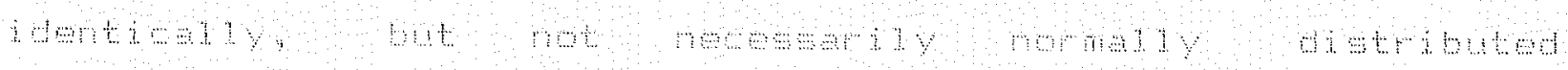

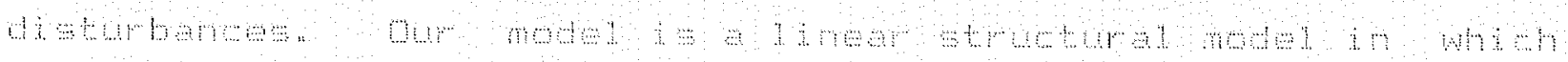

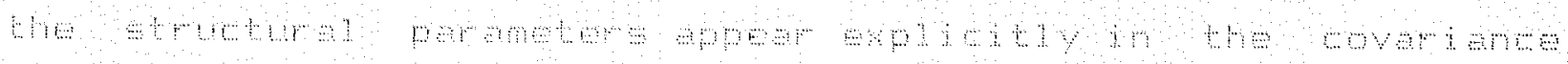

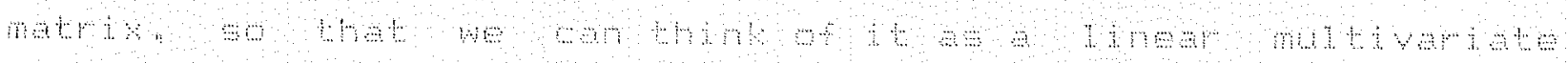

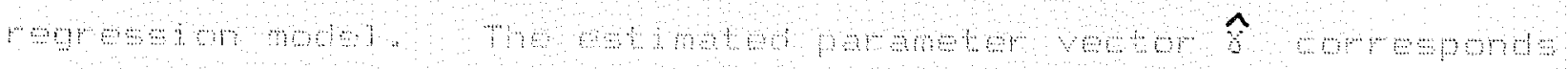
co m s -

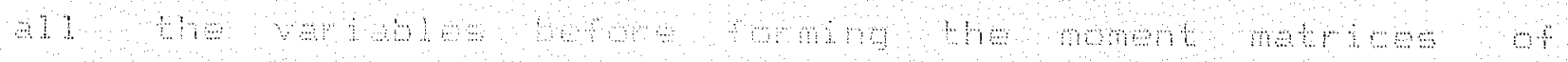

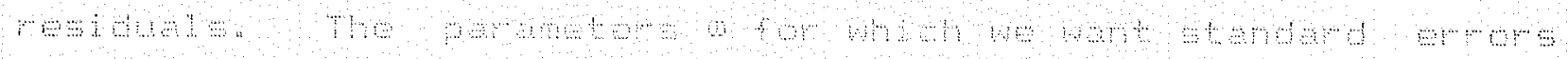




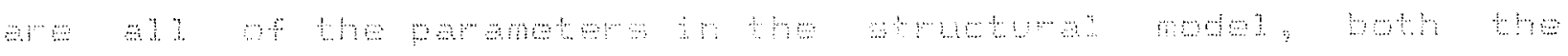

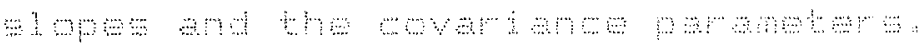

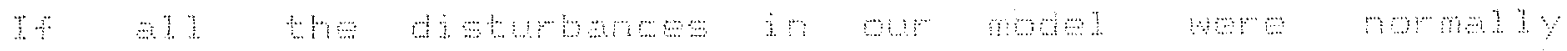

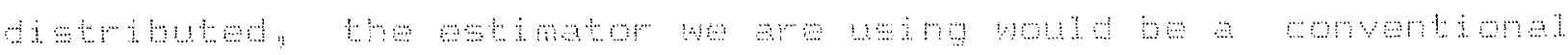

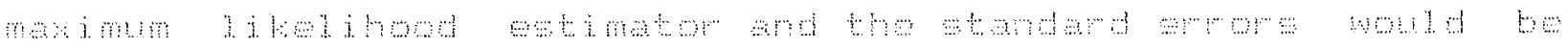

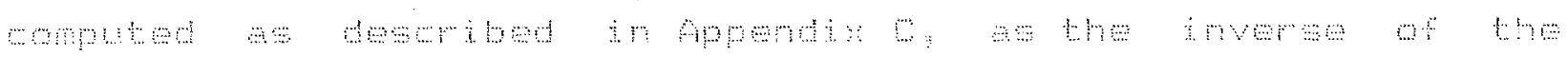

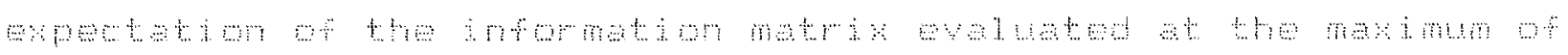

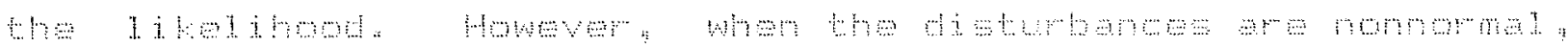

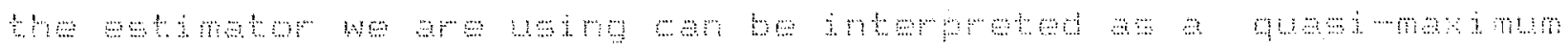

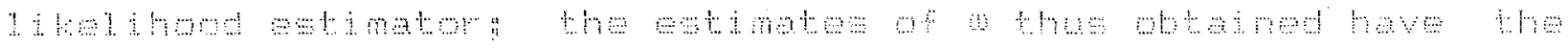

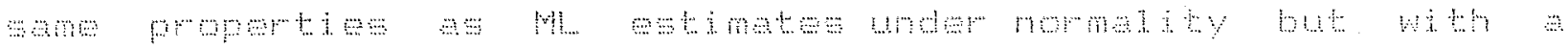

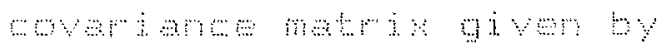

$$
V(\hat{\omega})=\frac{1}{N} H_{\omega \omega}^{-1}(\hat{\gamma}, \hat{\omega}) G_{\omega \omega}(\hat{\gamma}, \hat{\omega}) H_{\omega \omega}^{-1}(\hat{\gamma}, \hat{\omega})
$$

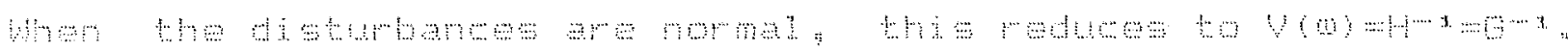

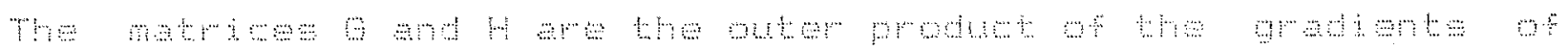

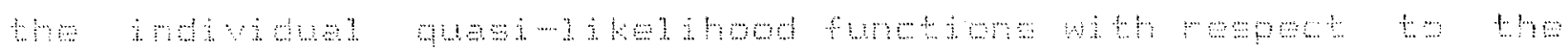

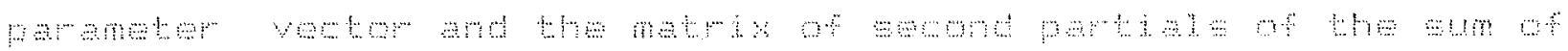

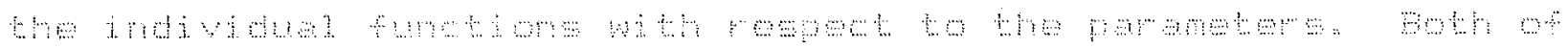

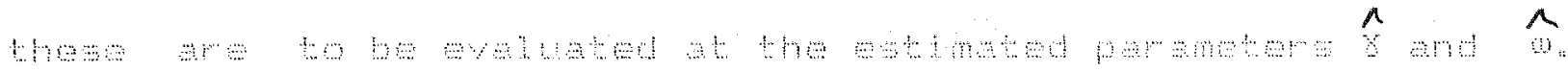

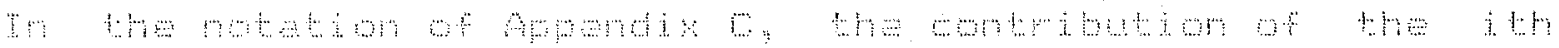

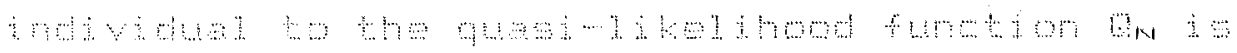

$$
\ldots-\frac{1}{2}\left\{\ln |\Sigma(\theta)|+\operatorname{tr} \Sigma(\theta)^{-1} S_{i}\right\}
$$

whro we haw whm 


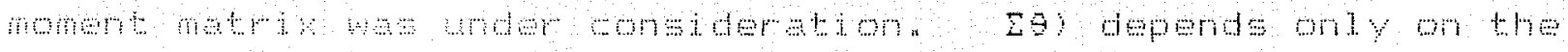

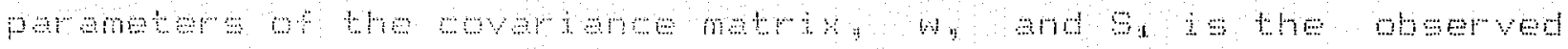

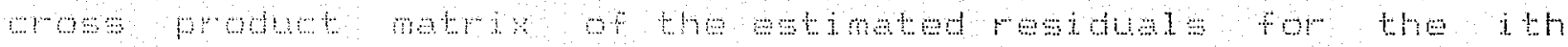

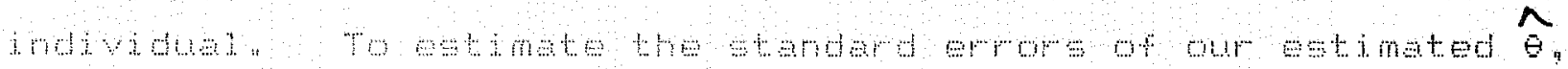

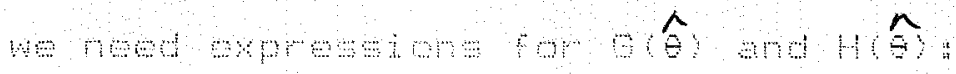

$$
\begin{aligned}
& \Delta(\theta)=\frac{1}{N} \sum_{i=1}^{N}\left[\frac{\partial q_{i}}{\partial \theta} \frac{\partial q_{i}}{\partial \theta^{\prime}}\right]_{\hat{\theta}} \\
& H\left(\theta--\left.\frac{\partial^{2} q_{N}}{\partial \theta \partial \theta^{\prime}}\right|_{\hat{\theta}}\right.
\end{aligned}
$$

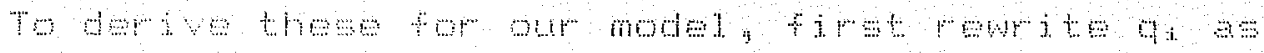

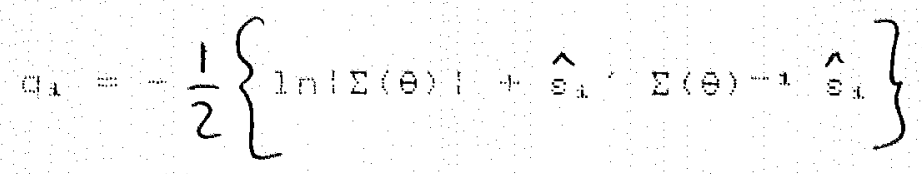

mere $\hat{\Xi}_{\mathrm{i}}$ are the estimated resdud a fhen

$$
\frac{\partial q_{i}}{\partial \theta_{k}}=-\frac{1}{2} \operatorname{tr}\left\{\Sigma^{-1} \frac{\partial \Sigma}{\partial \theta_{k}}\left[I-S_{i} \Sigma^{-1}\right]\right\}
$$

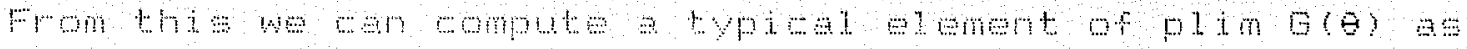

$$
\sigma_{n=1}=\frac{1}{4}\left[\operatorname { t r } \{ \frac { \partial \Sigma } { \partial \theta _ { k } } \frac { \partial \Sigma } { \partial \theta _ { l } } \Sigma ^ { - 4 } [ \frac { 1 } { N } \sum _ { i = 1 } ^ { N } S _ { i } S _ { i } ] \} \left[-\left[\operatorname{tr} \Sigma^{-1} \frac{\partial \Sigma}{\partial \theta_{k}}\right]\left[\operatorname{tr} \Sigma^{-1} \frac{\partial \varepsilon}{\partial \theta_{l}}\right]\right.\right.
$$

and tyat element of plin H(d)

$$
H_{k=1}=-\frac{1}{2} \operatorname{tr}\left\{\frac{\partial \Sigma}{\partial \theta_{k}} \frac{\partial \Sigma}{\partial \theta_{l}} \Sigma^{-2}\right\}
$$

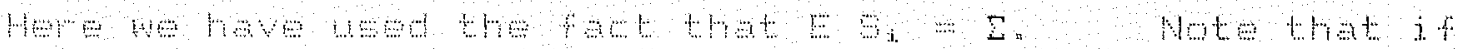

45 


$$
E \frac{1}{N} \sum_{i=1}^{N} S_{i}^{2}=3 \Sigma^{2},
$$

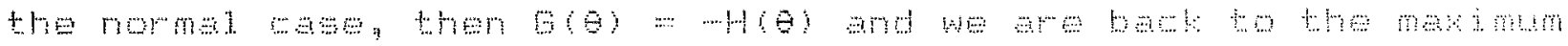

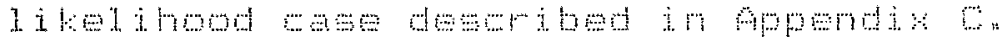

